\title{
Investigation of Land Subsidence Based on the Column Element Settlement Model in a Soft-Soil Area
}

\author{
Yang Chen, ${ }^{1}$ Wen Zhao $\left(\mathbb{D},{ }^{1}\right.$ Yong Huang $\mathbb{D}^{2},{ }^{2}$ and Pengjiao Jia ${ }^{1}{ }^{1}$ \\ ${ }^{1}$ School of Resources and Civil Engineering, Northeastern University, Shenyang, China \\ ${ }^{2}$ Department of Earth Science and Engineering, Hohai University, Nanjing, China \\ Correspondence should be addressed to Wen Zhao; wenneu@163.com and Pengiiao Jia; jpengjiao@163.com
}

Received 10 December 2018; Revised 1 March 2019; Accepted 31 March 2019; Published 19 May 2019

Academic Editor: Andrew H. Manning

Copyright (C) 2019 Yang Chen et al. This is an open access article distributed under the Creative Commons Attribution License, which permits unrestricted use, distribution, and reproduction in any medium, provided the original work is properly cited.

\begin{abstract}
The Su-Xi-Chang area is located in the Yangtze River Delta in southeastern Jiangsu Province, China. More than $2 \mathrm{~m}$ cumulative land subsidence has occurred since 1980s. A range of monitoring programs, geological investigations, and numerical modeling has been implemented in order to establish a regional rehabilitation plan. In this paper, the column element settlement model (CESM) has been established to investigate the coupling effect of soil self-weight, upper loads, and groundwater withdrawal on land subsidence. The model has been verified by comparing with the land subsidence records in Changzhou and further applied to the investigation area. The results show that extensive groundwater withdrawal is the main cause of the land subsidence. Settlement caused by soil self-weight increases with the depth and decreases with upper loads, while settlement caused by upper loads increases with the intensity of upper loads and decreases with depth. The proportion of ground settlement caused by soil self-weight, upper loads, and groundwater withdrawal is also investigated.
\end{abstract}

\section{Introduction}

Land subsidence is an environmental geological phenomenon which may cause significant damage and heavy economic losses. Ground water exploration and high-rise building construction are the main anthropogenic activities that induce notable land subsidence [1-3]. All these human activities increase both the dynamic and static loading in soils which result in the compression of soil layers [4-6]. Significant land subsidence is induced by the superimposition effect of groundwater withdrawal, soil self-weight, and upper loads [7]. Groundwater drawdown is the main culprit that could significantly induce ground settlement by increasing the effective stress of soils [8]. Massive exploration of groundwater leads to the decreasing of the water table as well as the ground elevation [9-12]. Many researchers [13, 14] proved that the effect of soil sedimentation and continuous soil consolidation cannot be neglected. Ground movement also occurs with the change of the stress state due to upper loads from buildings and foundations, which could lead to severe volumetric changes within the soil [7]. The relationship between ground settlement and consolidation time under different ground water tables was also proposed in some literatures [15-18]. Li [19] did further study on ground settlement caused by soil self-weight, indicating that soil selfweight increases nonlinearly with depth. The impact of sedimentation on ground settlement increases with upper loads, soil compressibility, and soil thickness [20-22].

Analytical expressions were derived to calculate the excess pore water pressure and settlement caused by different types of loading. Shi et al. [23] proposed a 3D groundwater mode and a 1D deformation model to simulate the groundwater level and soil deformation. Some practical methods are also available, such as the relationships among effective soil weight and total settlement of normally consolidated clay [24]. With very distinguished soil properties, the Su-XiChang area has experienced the most serious land subsidence due to excessive groundwater withdrawal in the late 1980s. More than $2 \mathrm{~m}$ cumulative land subsidence caused significant damage and heavy economic losses [25]. The Su-Xi-Chang area is also one of the most known in the world for the presence of earth fissures which has been observed within the 


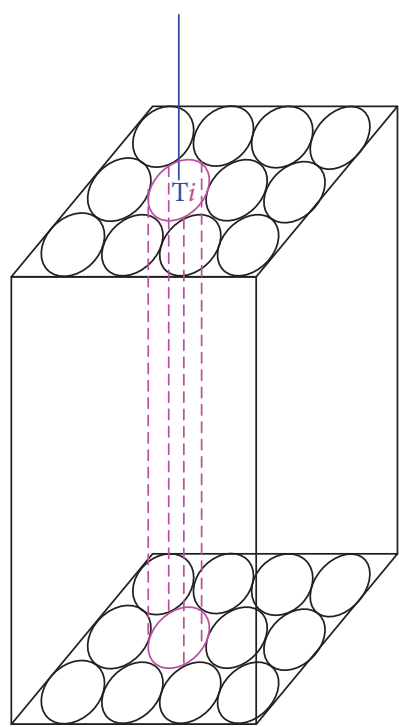

(a) Cylindrical element

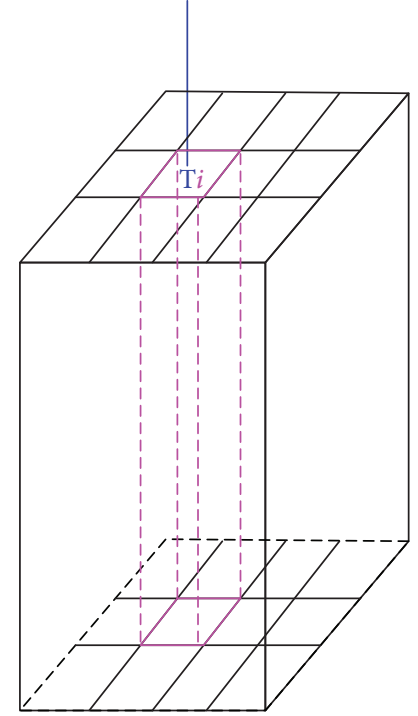

(b) Prismatic element

FIGURE 1: Schematic diagram of CESM.

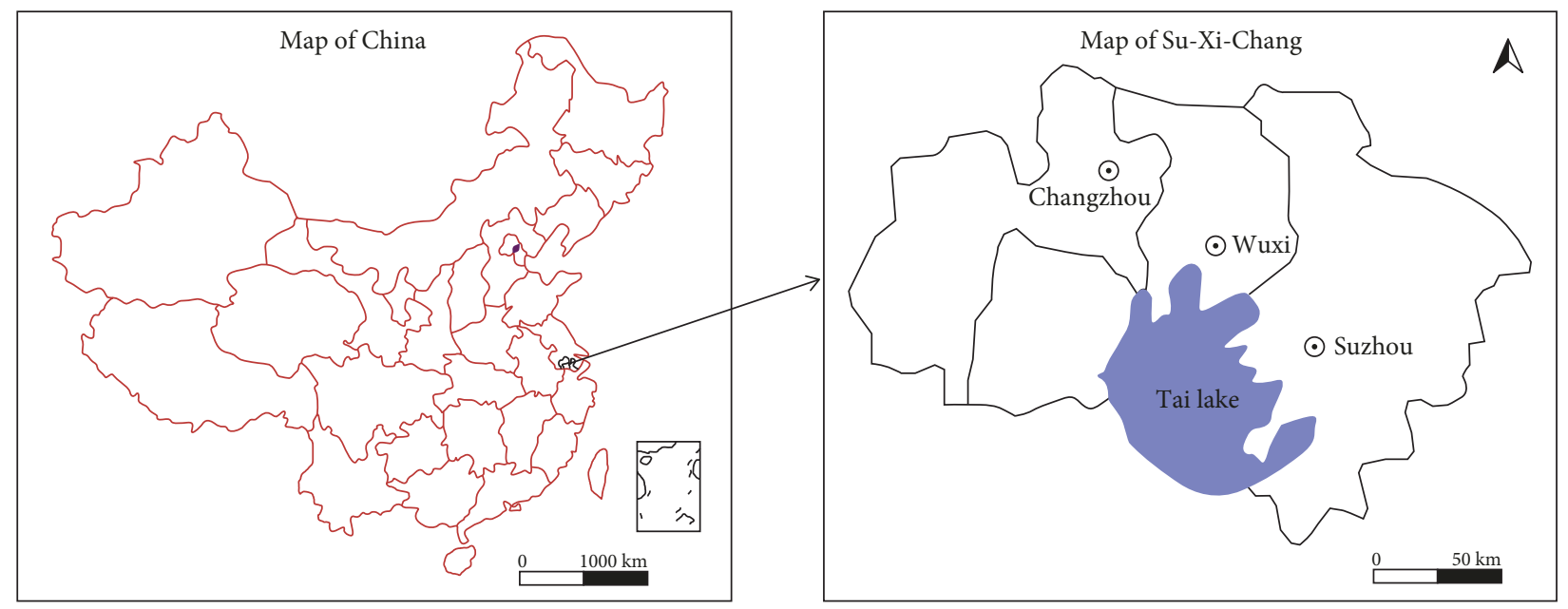

Figure 2: Map of the Su-Xi-Chang area in China.

areas and along the boundaries of these areas by many researchers $[26,27]$. A novel approach to simulate the soil deformation has been introduced by Chen et al. [28]. From the geological investigation report of this area, groundwater is mainly stored in aquifers and some of them are stored in clay and silty clay layers due to the wide distribution of low-permeability soil layers. Previous studies mainly focus on the homogeneous isotropic properties of hydrogeological parameters in soil layers, which is not suitable for the real cases $[2,5]$. The variation of soil parameters in horizontal directions may cause difference in land subsidence which is the main concern in practical engineering.

The column element settlement model (CESM) is introduced in the present work to consider different characteristics of soil layers in horizontal direction. The study area is divided into several subareas in horizontal direction. Relative soil parameters are assigned to corresponding soil column according to the geological survey data. The accuracy of this proposed method was assessed by comparing numerical results with land subsidence records in study areas. Then the developed approach is applied to simulate the coupling effect of land subsidence induced by soil self-weight, upper loads, and groundwater withdrawal. The proportion and evolution of land subsidence induced by soil self-weight, upper loads, and groundwater withdrawal were discussed.

\section{Methodology}

2.1. Establishment of CESM. There are many limitations to consider the soil as homogeneous isotropic media because soils are always a three-dimensional medium with the physical, mechanical, and hydrogeological parameter variations. CESM was proposed to depict the differences of 
TABLE 1: Material parameters for different soil layers in the study area.

\begin{tabular}{|c|c|c|c|c|c|c|c|c|}
\hline \multirow{2}{*}{ Parameter } & \multirow{2}{*}{ Name } & \multicolumn{5}{|c|}{ Aquifer } & \multirow{2}{*}{$\begin{array}{c}\text { Low-permeability layer } \\
1,2,3,4\end{array}$} & \multirow{2}{*}{ Unit } \\
\hline & & Unconfined aquifer & $\mathrm{I}_{\text {upper }}$ & $\mathrm{I}_{\text {lower }}$ & II & III & & \\
\hline Unsaturated density & $\gamma_{\text {unsat }}$ & 17.0 & 17.5 & 16.0 & 18.0 & 17.0 & 16.0 & $\mathrm{kN} / \mathrm{m}^{3}$ \\
\hline Saturated density & $\gamma_{\text {sat }}$ & 20.0 & 20.0 & 18.5 & 20.0 & 19.5 & 18.0 & $\mathrm{kN} / \mathrm{m}^{3}$ \\
\hline Horizontal hydraulic conductivity & $K_{\mathrm{h}}$ & 4.0 & 3.5 & 0.1 & 0.05 & 0.008 & 0.0001 & $\mathrm{~m} / \mathrm{d}$ \\
\hline Vertical hydraulic conductivity & $K_{\mathrm{v}}$ & 2.0 & 1.75 & 0.05 & 0.025 & 0.004 & 0.00005 & $\mathrm{~m} / \mathrm{d}$ \\
\hline Elasticity modulus & $E$ & 14.6 & 14.4 & 14.8 & 12.6 & 13.0 & 4.56 & $\mathrm{MPa}$ \\
\hline Poisson's ratio & $v$ & 0.3 & 0.31 & 0.3 & 0.32 & 0.33 & 0.35 & \\
\hline Cohesion & $c$ & 8.3 & 8.1 & 8.1 & 4.5 & 11.0 & 25.0 & $\mathrm{kPa}$ \\
\hline Internal friction angle & $\varphi$ & 34.3 & 33.0 & 33.0 & 32.0 & 35.0 & 11.0 & $\circ$ \\
\hline Dilatancy angle & $\psi$ & 0.0 & 0.0 & 0.0 & 0.0 & 0.0 & 0.0 & $\circ$ \\
\hline
\end{tabular}

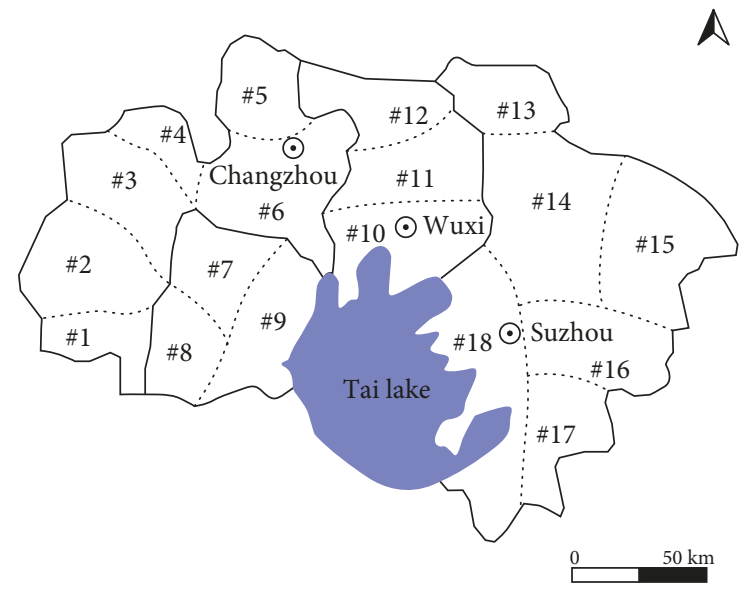

FIGURE 3: Column element partitions in the study area.

hydrogeological structures, parameters, and physical mechanical index of soil layers in horizontal direction with the following properties:

(1) CESM is a concept based on effective stress principles, that is, the total stress, effective stress, and pore water pressure are in a dynamic equilibrium. Soil compression increases with the increase of effective stress and decrease of pore water pressure

(2) The column element shape can be either a cylinder or prism according to the geographic properties in the study area, and the soil parameters among each element are mutually independent (Figure 1). The settlement at the center of each element represents the settlement of this element. The accuracy of this model can be improved by the smaller element size. Soil inhomogeneity and anisotropy can be reflected by different partitions within the study area. The settlement distribution of the whole study area can be obtained through each element settlement

(3) The sizes and shapes of each column can vary randomly based on the partitions of the study area. The soil parameters in vertical direction can be obtained from the borehole survey data, while the horizontal soil parameters of each column can be obtained by collecting the borehole data in different areas

\section{Solution of CESM}

\subsection{Materials and Parameters}

3.1.1. Regional Geology and Hydrogeology. The Su-Xi-Chang area is located in the Yangtze River Delta, Jiangsu Province, southeastern China, bordering the west of Shanghai (Figure 2). It covers over a 17000 square kilometer area with a large population of over 21 million. The average elevation is less than $6 \mathrm{~m}$ above the sea level [23].

Due to the lack of in situ physical and mechanical parameters, the engineering geological analogy method was adopted to obtain the soil parameters of the study site [29]. The engineering geology analogy is mainly carried out based on the following aspects: regional location, lithological characteristics, and types of aquifer and aquitard.

Physical and mechanical parameters of Changzhou Xinzha, Wuxi Meilianghu Pumping Station Project, Taicang Danghe River hub project, Runyang Yangtze River Bridge south anchorage base, Taizhou Yangtze River Bridge Jiajiang base, and Sutong Yangtze River Bridge base were collected and applied to other areas with similar regional location, lithological characteristics, or types of aquifer and aquitard. The maximum and minimum values of the physical and mechanical parameters of the same stratum are collected and analyzed. The soil parameters of the Su-Xi-Chang area can be derived by the interpolation of obtained soil parameters in the study area.

Since the land subsidence is well known in the study area, several geological surveys have been conducted by the local Geological Survey Institute. Considering the soil parameters in Table 1, they have been derived from the Groundwater Resources Evaluation and Planning Report in the study area. Sixteen drilling pumping tests and geotechnical tests have been conducted to obtained the hydrogeological and physical mechanical parameters in the study area. The in situ test indicates that the mechanical properties of the soil in different elements share almost the same parameters in the same 
TABLE 2: Material parameters for different partition elements in the Su-Xi-Chang area.

\begin{tabular}{|c|c|c|c|c|c|c|}
\hline Partition number & $\# 1$ & $\# 2$ & $\# 3$ & $\# 4$ & $\# 5$ & $\# 8$ \\
\hline Transmissibility $\left(\mathrm{m}^{2} / \mathrm{d}\right)$ & 2000 & 1980 & 1500 & 1250 & 1200 & 1100 \\
\hline Storage coefficient & $4.00 \times 10^{3}$ & $3.80 \times 10^{3}$ & $3.20 \times 10^{3}$ & $8.60 \times 10^{3}$ & $7.50 \times 10^{3}$ & $5.00 \times 10^{3}$ \\
\hline Partition number & \#10 & $\# 11$ & $\# 12$ & $\# 6$ & \#7 & $\# 9$ \\
\hline Transmissibility $\left(\mathrm{m}^{2} / \mathrm{d}\right)$ & 1050 & 800 & 500 & 480 & 460 & 450 \\
\hline Storage coefficient & $4.30 \times 10^{3}$ & $3.60 \times 10^{3}$ & $2.50 \times 10^{3}$ & $2.30 \times 10^{3}$ & $2.10 \times 10^{3}$ & $2.00 \times 10^{3}$ \\
\hline Partition number & $\# 18$ & $\# 13$ & $\# 14$ & $\# 15$ & $\# 16$ & $\# 17$ \\
\hline Transmissibility $\left(\mathrm{m}^{2} / \mathrm{d}\right)$ & 420 & 400 & 382 & 350 & 300 & 100 \\
\hline Storage coefficient & $2.00 \times 10^{3}$ & $1.50 \times 10^{3}$ & $1.30 \times 10^{3}$ & $1.20 \times 10^{3}$ & $1.00 \times 10^{3}$ & $6.00 \times 10^{3}$ \\
\hline
\end{tabular}

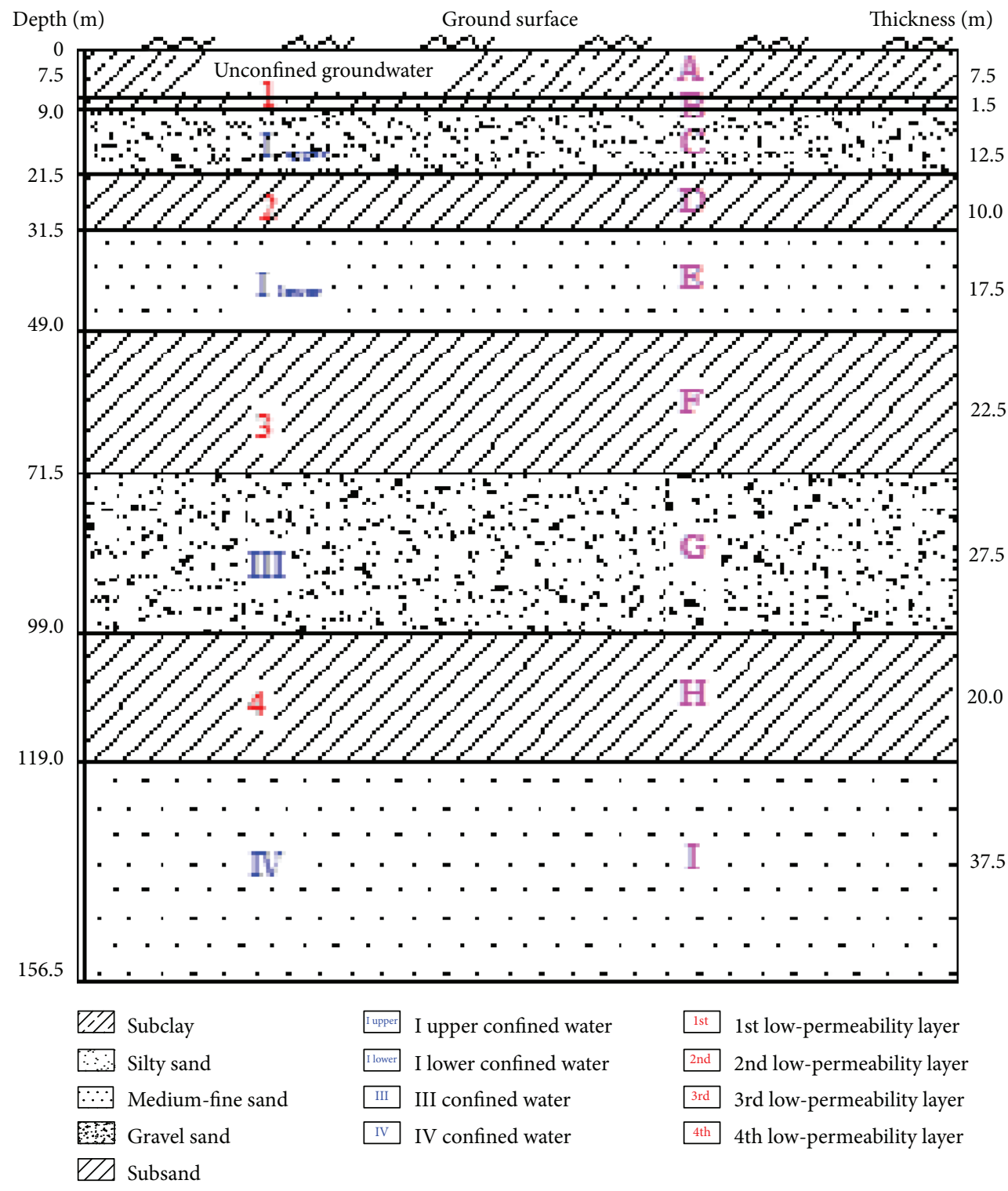

FIGURE 4: Hydrostratigraphy along the cross-section in the Changzhou area.

layer except two parameters, that is, transmissibility and water storage coefficient. Material parameters used in CESM numerical simulations are depicted in Table 1.
The whole study area is divided into 18 subareas in horizontal direction according to the soil characteristics from the Groundwater Resources Evaluation and Planning Report 


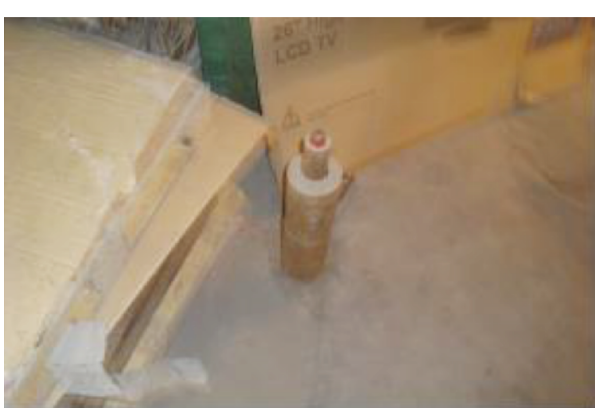

(a)

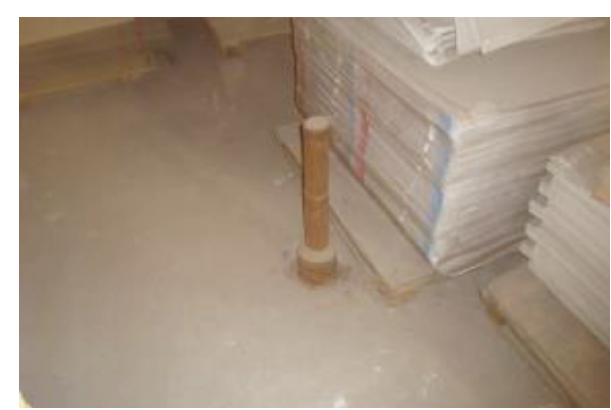

(b)

Figure 5: Hierarchical signs in the Changzhou Qingliang primary school.

TABLE 3: The thickness of soil layers.

\begin{tabular}{lcccccccc}
\hline Layer & L\#1 & L\#2 & L\#3 & L\#4 & L\#5 & L\#6 & L\#7 & L\#8 \\
\hline Depth $(\mathrm{m})$ & 18.5 & 35.4 & 71.32 & 92.8 & 107.8 & 117.65 & 143.6 & 156.5 \\
\hline
\end{tabular}

in Suzhou, Wuxi, and Changzhou (Figure 3). The transmissibility and water storage coefficient of different aquifers are calculated according to the drilling pumping test data. It can be seen from the table that the maximum transmissibility is 20 times larger than the minimum transmissibility and the maximum water storage coefficient is about 67 times the minimum storage coefficient (Table 2). It is also indicated from the table that the physical and mechanical properties of the aquifer as well as the hydrogeological parameters show a large discrepancy in different regions.

There is a well-established land subsidence station with multilayered extensometers to monitor the strata compaction in Changzhou. Thus, Changzhou is selected as the representative area to investigate the land subsidence caused by groundwater withdrawal, self-weight, and upper loading to lower the computing efforts. As it is well known, different hydrostratigraphic units have different kinds of deformation and the same unit may also exhibit different deformation characteristics, such as elasticity and elastoplasticity at different locations in different periods. Shi et al. [23] found that the deformation of both the sandy aquifer and the clay aquifer mainly possesses elastoplastic behavior. In this work, a simulation is performed based on the Mohr-Coulomb constitutive model and the soil performs elastoplastic behavior. According to the local geological soil properties of the study area, a conceptual model in Changzhou can be proposed by assuming as a plane strain problem [30]. Based on stratigraphic data and soil properties, the multilayer aquifer system consists of four aquifer units including four confined aquifers and four aquitard units. The left and right boundaries are set as a fixed water level with no horizontal displacement. The bottom boundary of the study area is assumed to be incompressible and impermeable.

The depth of the column element model is $156.5 \mathrm{~m}$ according to the average thickness of soil layers. A, B, C, D, E, F, G, H, and I located at the middle of each layer are selected as the monitoring points to indicate the settlement responses of each layer. The buried depths of the monitoring point from A to I are $3.75 \mathrm{~m}, 8.25 \mathrm{~m}$,
$15.25 \mathrm{~m}, 26.5 \mathrm{~m}, 40.25 \mathrm{~m}, 60.25 \mathrm{~m}, 85.25 \mathrm{~m}, 109 \mathrm{~m}$, and $137.75 \mathrm{~m}$, respectively. Five soil layers are considered through the soil profile of the study area. More specifically, the soil type is subclay, silty sand, medium-fine sand, gravel sand, and subsand from the top to the bottom soil layers. The cross-section of the hydrostratigraphy of the Changzhou area is presented in Figure 4.

3.2. Verification of CESM. Monitored data in Changzhou was adopted to verify the established CESM in the study area. Hierarchical signs for the monitored settlement in the Changzhou Qingliang primary school are shown in Figure 5.

3.2.1. Measured Settlement in Changzhou. Monitoring of ground settlement and piezometric head has been carried out since the end of the $20^{\text {th }}$ century. The depth of each monitoring point is shown in Table 3. Figure 6 depicted the cumulative ground settlement of the Changzhou Qingliang primary school from year 1984 to year 2000. Settlement at the end of each year was adopted to conduct comparison. Land subsidence increases with the investigation time and depth. Layer 3 and layer 4 account for most of the total settlement through the whole monitoring period.

3.2.2. Land Subsidence using CESM. The monitoring period in the Changzhou Qingliang primary school is from year 2000 to year 2005 for both the groundwater level and land subsidence, and thus, the effective comparison between monitored and calculated ground settlement is from year 2000 to 2005. The numerical model was established to achieve the ground settlement in Changzhou. The obtained soil parameters are used to predict the settlement of each layer.

The measured groundwater level was adopted to simulate the real cases. The upper load intensity is assumed to be $1 \mathrm{kPa}$. The ground settlement of each layer under different depths in partition \#4 was selected to conduct comparison between the monitored settlement and calculated settlement. Figure 7 shows that the relative difference between the calculated settlement and measured settlement data can be neglected by given material parameters. The total settlement increases with the groundwater level. Monitored and calculated settlements from the ground surface to layer 3 show good agreement in years 2000, 


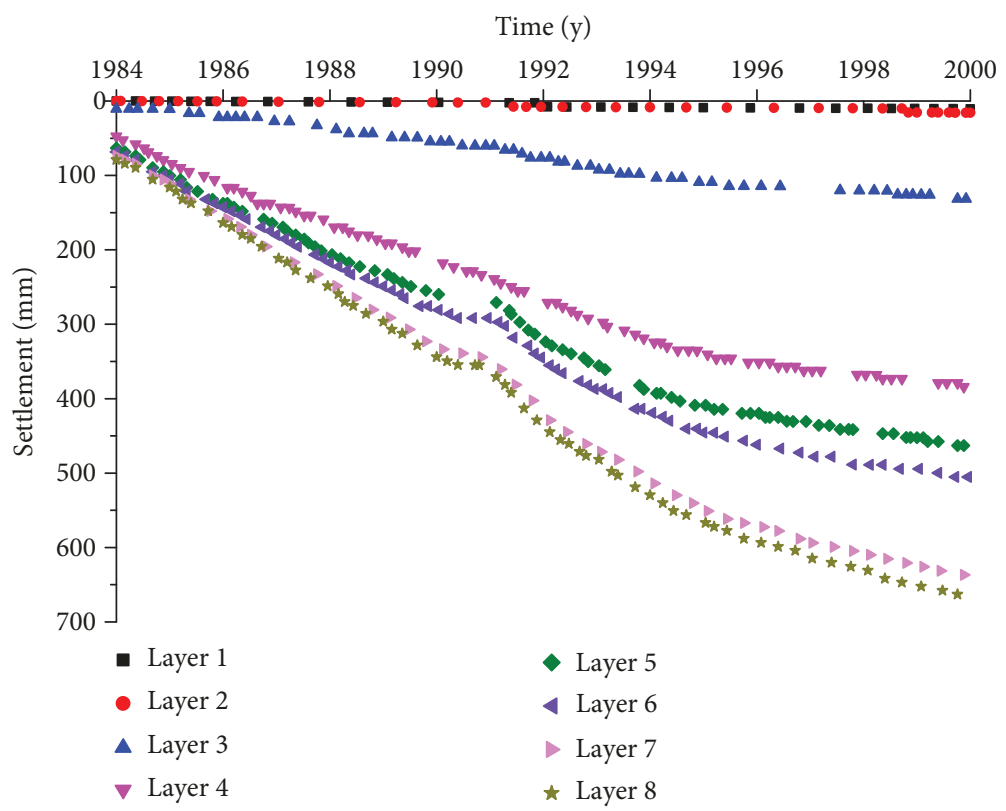

Figure 6: Settlement records of the Changzhou Qingliang primary school.

2003, and 2004 (Figure 7). Settlements calculated in years 2001 and 2002 are lower than monitored settlement data. The settlement calculated in year 2005 is higher than the monitored settlement because of the upper load changes in the monitoring site at that year. This discrepancy may result from the uncertainties of soil parameters and the variation of groundwater levels in real cases. Calculated and monitored settlements from layer 4 to layer 7 exhibit the same trend which means that the numerical model confirms with the monitored data (Figure 8). Thus, the CESM can be adopted to obtain the land subsidence in the whole study area.

\section{Results and Discussion}

4.1. Ground Settlement Induced by Self-Weight. The ground settlement caused by soil self-weight is calculated by the layer-wise summation method [31]. The aquifer in the study area can be divided into several layers of different thickness $h_{1}, h_{2}, h_{3}, \ldots, h_{n}$, and the deformations of each layer are $S_{1}$, $S_{2}, S_{3}, \ldots, S_{n}$, and the total ground settlement is

$$
S=\sum_{i=1}^{n} S_{i}=S_{1}+S_{2}+\cdots+S_{n}
$$

where $S$ is the total ground settlement, $S_{i}$ is the ground settlement of each layer, $i$ is the number of soil layer, and it can be calculated as

$$
S_{i}=\left(\frac{\alpha_{i}}{1+e_{0}}\right)_{i} \sigma_{z i} h_{i}
$$

where $\alpha_{i}$ is the compression coefficient of layer $i, e_{0}$ is the void ratio before compression of layer $i, \sigma_{z i}$ is the additional stress in layer $i(\mathrm{kPa})$, and $h_{i}$ is the thickness of layer $i$.

The study area can be divided into 9 layers and 18 partitions according to the geological investigation. Unconfined aquifer, confined aquifer, and aquitard are distributed from top to the bottom. Settlement is different from layer to layer because of the variation of soil properties. The groundwater levels are $0 \mathrm{~m}, 7.5 \mathrm{~m}$, and $156.5 \mathrm{~m}$ below the ground surface. The calculated ground settlement under different groundwater levels is shown in Table 4.

4.2. Evolution of Aquifer Settlement with Time. The differential equation governing one-dimensional consolidation theory is as follows:

$$
C_{v} \frac{\partial^{2} u}{\partial z^{2}}=\frac{\partial u}{\partial t}
$$

where $C_{v}$ is the coefficient of consolidation of the soil, $u$ is the excess pore water pressure, $z$ is the distance measured downward from the surface of the consolidating layer, and $t$ is time [32].

The average degree of consolidation can be assumed as $U_{0}=10 \%, 20 \%, 40 \%, 60 \%, 80 \%$, and $90 \%$.

$$
U_{0}=1-\frac{8}{\pi^{2}}\left(e^{-\pi^{2} / 4 T_{v}}+\frac{1}{9} e^{-\left(9 \pi^{2} / 4\right) T_{v}}+\cdots\right),
$$

where $T_{v}=K\left(1+e_{m}\right) t / 0.1 \gamma_{w} \sigma_{\mathrm{a}} H^{2}$ is the dimensionless time factor and can be derived through $U_{0}$ and $\sigma_{\mathrm{a}} \cdot \sigma_{\mathrm{a}}=\sigma_{t}-p$, where $\sigma_{\mathrm{a}}$ is additional stress, $\sigma_{t}$ is total stress, $p$ is the pore water pressure. $e_{m}$ is the average void ratio of soil during consolidation, and $H, K$, and $\gamma_{w}$ are the thickness, permeability, 


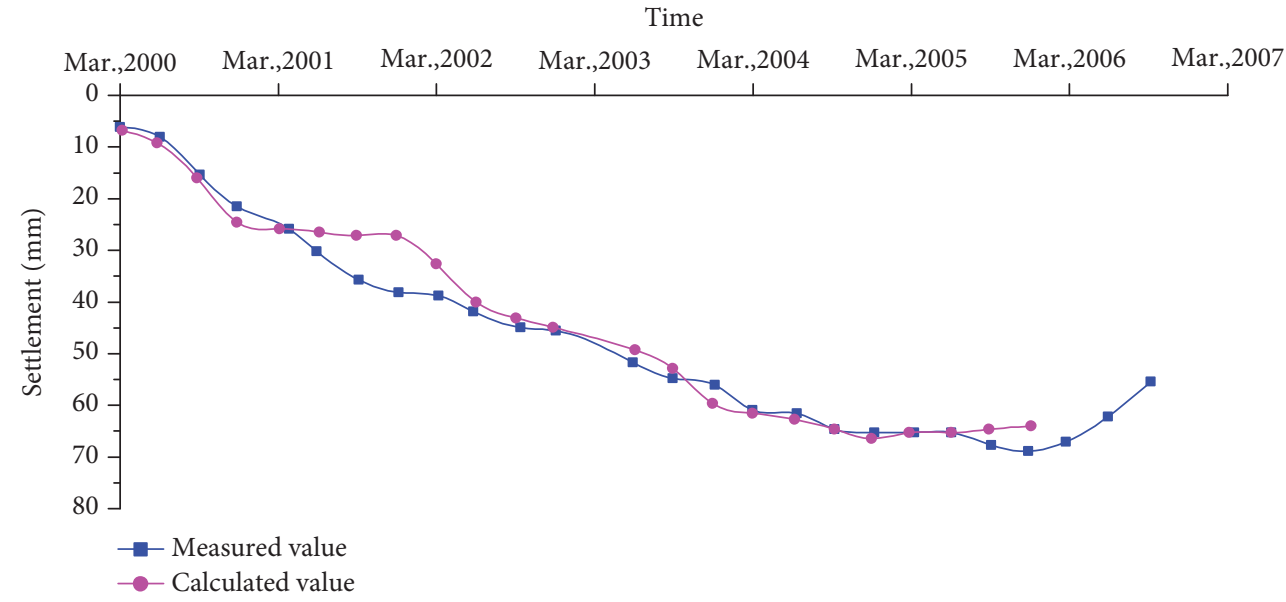

(a) Surface point

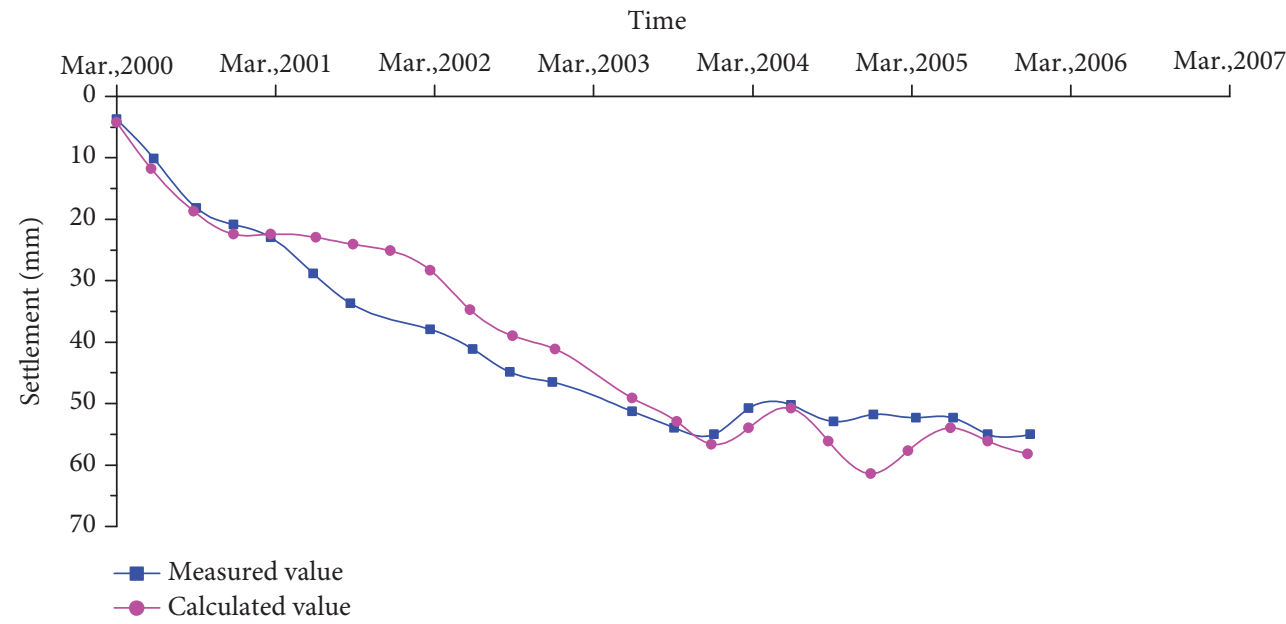

(b) Layer 1

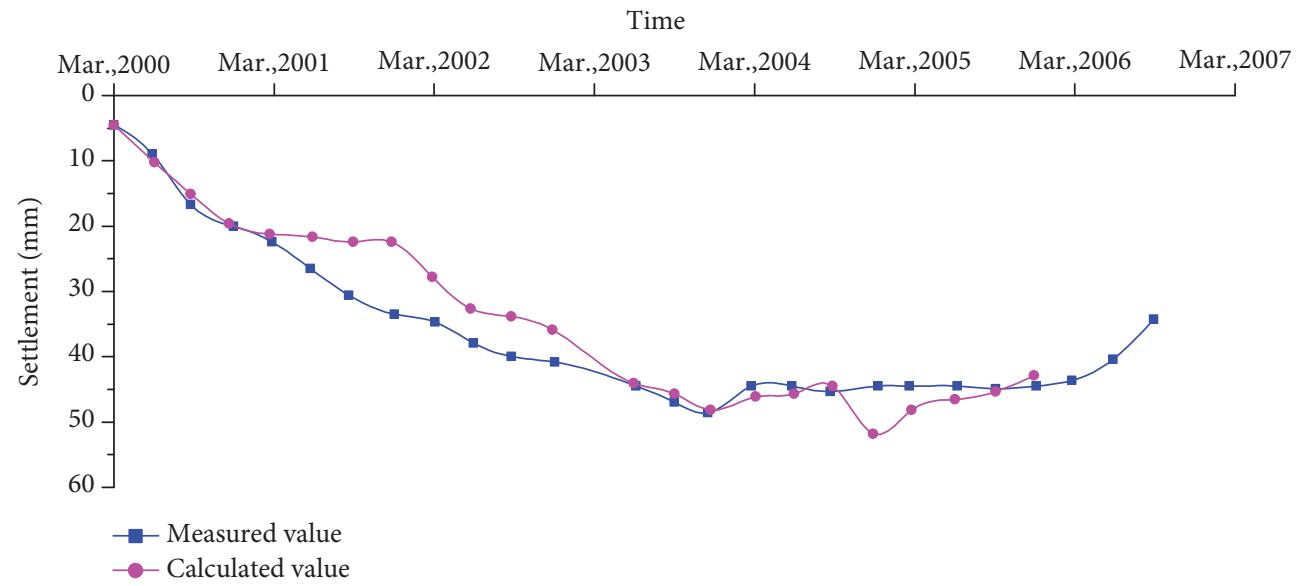

(c) Layer 3

Figure 7: Comparison between measured and calculated settlements of soil layers. 


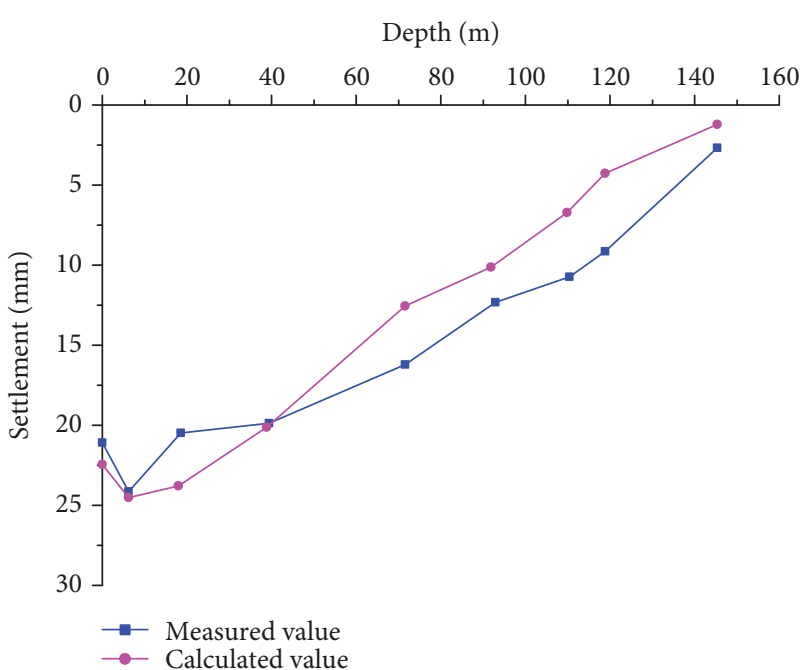

Figure 8: Comparison between measured and calculated settlements at different depths in year 2000.

TABLE 4: Ground settlement under different groundwater levels.

\begin{tabular}{lccc}
\hline \multirow{2}{*}{ Type of aquifer } & \multicolumn{3}{c}{ Settlement in different groundwater } \\
& $D=0 \mathrm{~m}$ & $D=-7.5 \mathrm{~m}$ & $D=-156.5 \mathrm{~m}$ \\
\hline Unconfined groundwater & 19.3 & 32.7 & 32.7 \\
Low permeable layer 1 & 26.6 & 43.9 & 45.9 \\
I $_{\text {upper }}$ & 129.8 & 175.3 & 226.5 \\
Low permeable layer 2 & 552.6 & 667.8 & 987.4 \\
I lower $_{\text {Low permeable layer 3 }}$ & 433.2 & 495.3 & 792.5 \\
II & 2619 & 2878.1 & 4886.1 \\
Low permeable layer 4 & 1655 & 1769.6 & 3094.3 \\
III & 4280 & 4510.1 & 8005.5 \\
Total settlement & 3560 & 3711.1 & 6646.2 \\
\hline
\end{tabular}

and weight of soil, respectively. The coefficient of compressibility and equivalent coefficient of compressibility can be derived from the following equation $[9,15]$ :

$$
\begin{aligned}
& \alpha_{i}=\left(\frac{1+e_{0}}{E_{s}}\right)_{i}, \\
& \alpha_{e}=\sum_{i=1}^{n} \frac{h_{i} \alpha_{i}}{h}=\sum_{i=1}^{n} \frac{h_{i}}{h}\left(\frac{1+e_{0}}{E_{s}}\right)_{i},
\end{aligned}
$$

where $\alpha_{e}$ is the equivalent coefficient of compressibility, which is calculated as $0.19 \mathrm{MPa}^{-1}$. $E_{s}$ is the elastic modulus, $h_{i}$ is the thickness of each soil layer, and $h$ is the total thickness of the aquifer. Consolidation coefficient can be derived by substituting the parameters in Table 1 into the following equation:

$$
C_{v}=\frac{K\left(1+e_{m}\right)}{0.1 \gamma_{w} \alpha_{e}}=3.58 \times 10^{5}\left(\frac{\mathrm{cm}^{2}}{a}\right),
$$

and the consolidation time can be expressed as follows:

$$
t=\frac{H^{2}}{C_{v}} T_{v} \approx 684 T_{v}(a)
$$

The evolution of ground settlement under different groundwater depths (GWD) is depicted in Table 5. Ground settlement under soil self-weight increases with the increase of settling time and groundwater depth.

4.3. Ground Settlement under Different Upper Loads. Numerical analysis was conducted to investigate land subsidence induced by different upper loads. Two scenarios were considered as follows:

(1) The groundwater table is assumed to be $0 \mathrm{~m}$ and load intensity is assumed to be $10 \mathrm{kPa}, 25 \mathrm{kPa}$, $35 \mathrm{kPa}, 50 \mathrm{kPa}$, and $80 \mathrm{kPa}$. Land subsidence of the study area under different load intensities is shown in Figures 9 and 10. It can be noted that the ground settlement increases gradually with the load intensity and time. Maximum land subsidence occurs at the surface of soil layers which indicates the depth effect of load intensity. Land subsidence decreases with the buried depth under the same load because the additional stress decreases with the soil depth, while it increases with the load intensity at the same monitoring point. The land subsidence increases linearly with the increase of loading time

Relationships between the upper loading and settlement of point $\mathrm{A}$, point $\mathrm{E}$, and point $\mathrm{H}$ in the unconfined aquifer, $\mathrm{I}_{\text {lower }}$ confined aquifer, and fourth aquitard were plotted in Figure 11. The load-settlement relationship of point $\mathrm{A}$, point $\mathrm{E}$, and point $\mathrm{H}$, i.e., equation (8), was also plotted in Figure 11. This relationship can be used to predict the land subsidence under different load intensities in the study area. The total land subsidence under different load intensities increases linearly with the load intensity and the depth, while the discrepancy between the real and predicted settlements may become larger under higher loading intensity due to plastic deformation of soil.

$$
\begin{aligned}
y & =0.0129 x-4 \times 10^{-9}, \\
R^{2} & =1.0, \\
y & =0.0101 x+2 \times 10^{-7}, \\
R^{2} & =1.0, \\
y & =0.0033 x-1 \times 10^{-8}, \\
R^{2} & =1.0,
\end{aligned}
$$

where $x$ represents the magnitude of load intensity and $y$ represents land subsidence. 
TABLE 5: Time effect of ground settlement under different groundwater levels.

\begin{tabular}{|c|c|c|c|c|c|}
\hline \multirow{2}{*}{ Degree of consolidation } & \multirow{2}{*}{ Time factor } & \multirow{2}{*}{ Time $(y)$} & \multicolumn{3}{|c|}{ Ground settlement $(\mathrm{mm})$} \\
\hline & & & $\mathrm{GWD}=0 \mathrm{~m}$ & $\mathrm{GWD}=-7.5 \mathrm{~m}$ & $\mathrm{GWD}=-156.5 \mathrm{~m}$ \\
\hline 0 & 0 & 0 & 0 & 0 & 0 \\
\hline 10 & 0.05 & 34.2 & 1300 & 1400 & 2500 \\
\hline 20 & 0.11 & 71.8 & 2700 & 2900 & 4900 \\
\hline 50 & 0.29 & 198.4 & 6600 & 7100 & 12400 \\
\hline 80 & 0.69 & 472 & 10600 & 11400 & 19800 \\
\hline 95 & 0.99 & 677.2 & 12600 & 13600 & 23500 \\
\hline
\end{tabular}

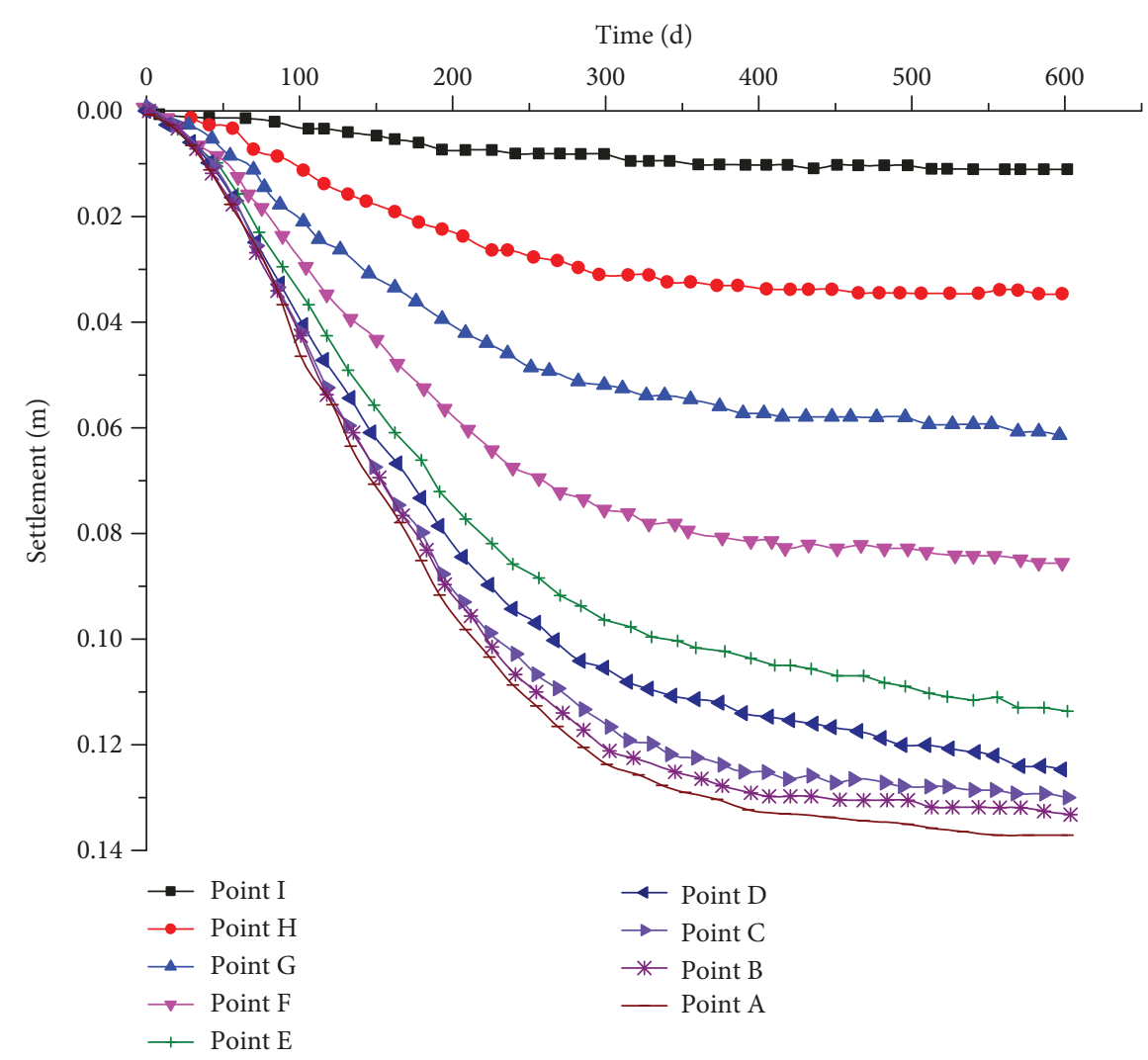

Figure 9: Ground settlement under $10 \mathrm{kPa}$ uniform load intensity.

(2) The groundwater table is assumed to be $4 \mathrm{~m}$ with a series variation of load intensity. Three scenarios were assumed, that is, soil self-weight changes linearly and load intensity increases first and then decreases to simulate the rising and falling of the groundwater table (Table 6)

As depicted in Figures 12-14, for case П-01, land subsidence increases with loading time and intensity and decreases with depth. For case $\Pi-02$, settlement of soil layers increases with load and then decreases due to the change of load intensity. Settlement changes in a hysteresis way compared to loading. For point $\mathrm{A}$, the ground settlement at the $4^{\text {th }}$ year is $4.2 \mathrm{~mm}$ less than the $7^{\text {th }}$ year under the same loading $40 \mathrm{kPa}$ and the ground settlement at the $1^{\text {st }}$ year is $16.7 \mathrm{~mm}$ less than the $10^{\text {th }}$ year under the same loading $10 \mathrm{kPa}$. For case $\Pi-03$, the land subsidence changes with loading in each soil layer.
4.4. Proportion of Land Subsidence Caused by Different Reasons. Three scenarios were considered including different groundwater levels and upper loadings. Land subsidence induced by different reasons in partition \#4 was investigated to emphasize the proportion of land subsidence induced by self-weight, upper loads, and groundwater withdrawal. The land subsidence induced by different reasons are normalized by dividing total ground settlement. For example, the percentage of ground settlement caused by pumping is calculated by $S_{\mathrm{p}}=\left(S_{\mathrm{t}}-S_{\mathrm{s}}-S_{\mathrm{l}}\right) / S_{\mathrm{t}}$, where $S_{\mathrm{p}}, S_{\mathrm{t}}, S_{\mathrm{s}}$, and $S_{\mathrm{l}}$ are the land subsidence induced by groundwater withdrawal, total ground settlement, the ground settlement induced by soil self-weight, and upper loads, respectively.

(1) The groundwater level directly decreases from $0 \mathrm{~m}$ to $4 \mathrm{~m}$ below the ground surface; the loading intensity is $1 \mathrm{kPa}$ 


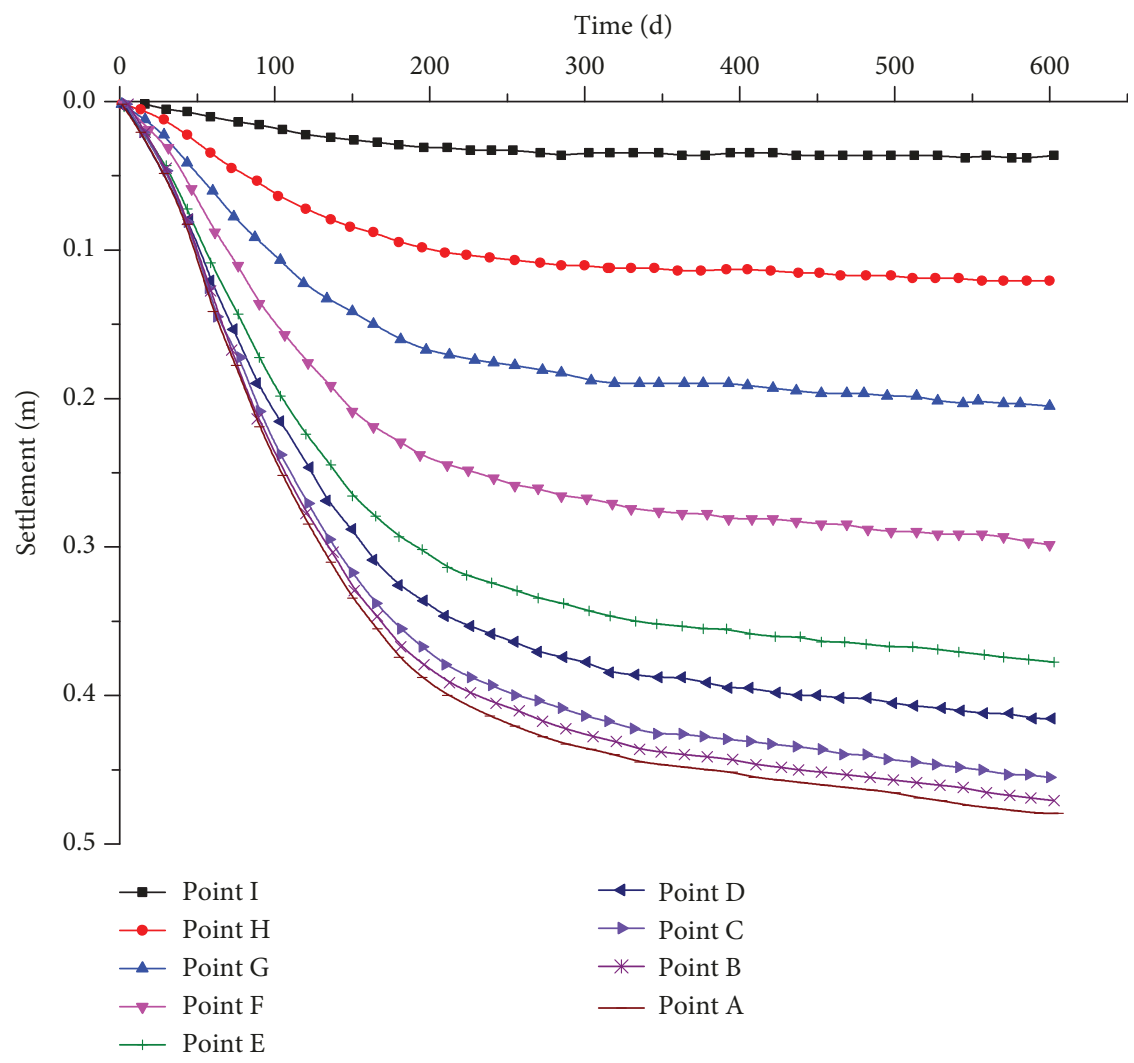

Figure 10: Ground settlement under $35 \mathrm{kPa}$ uniform load intensity.

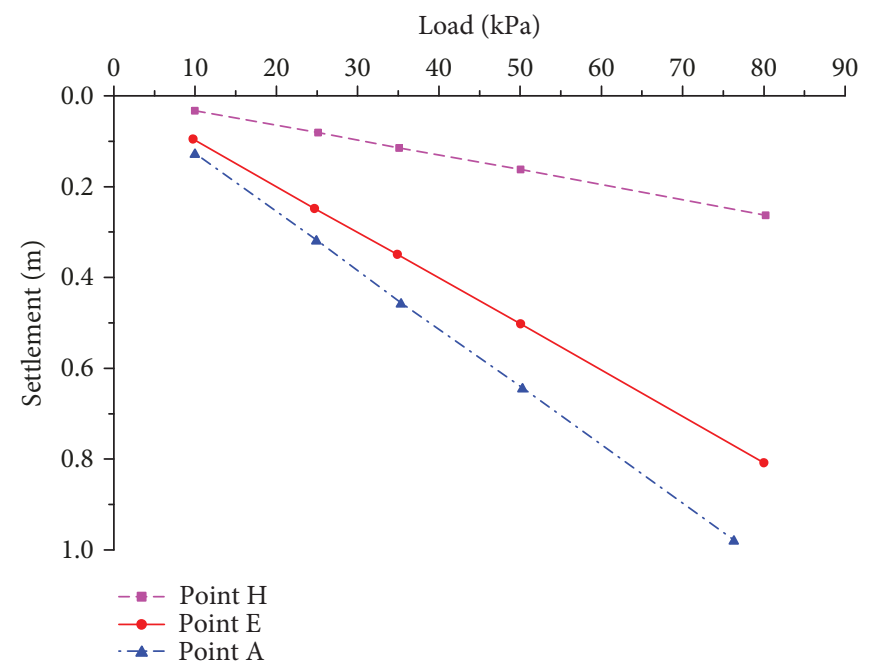

Figure 11: Variation of ground settlement with loading intensity.

TABLE 6: Load intensity varies with time (unit: $\mathrm{kPa}$ ).

\begin{tabular}{ccccccccccc}
\hline \multirow{2}{*}{ Plan } & 1 & 2 & 3 & 4 & 5 & 6 & 7 & 8 & 9 & 10 \\
\hline$\Pi-01$ & 10 & 20 & 30 & 40 & 50 & 60 & 70 & 80 & 90 & 100 \\
$\Pi-02$ & 10 & 20 & 30 & 40 & 50 & 50 & 40 & 30 & 20 & 10 \\
$\Pi-03$ & 10 & 20 & 30 & 10 & 0 & 60 & 25 & 50 & 35 & 35 \\
\hline
\end{tabular}

Comparison of settlement caused by self-weight, upper loading, and groundwater withdrawal is shown in Figure 15. Settlement caused by groundwater withdrawal and upper loading dominant from 0 to 200 years almost accounting for $97 \%$ of the total settlement. The settlement caused by self-weight gradually increases and reaches to $6.5 \%$ of the total settlement. However, settlement caused by drainage is higher than self-weight all the time. 


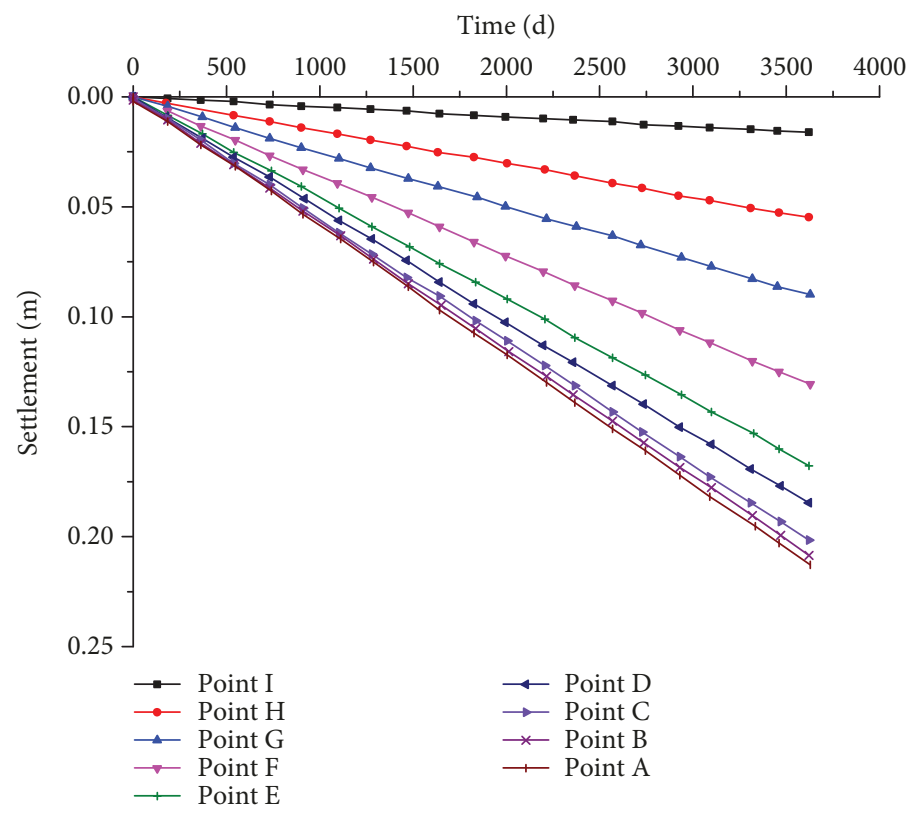

FIGURE 12: Ground settlement changing with time in case $\Pi-01$.

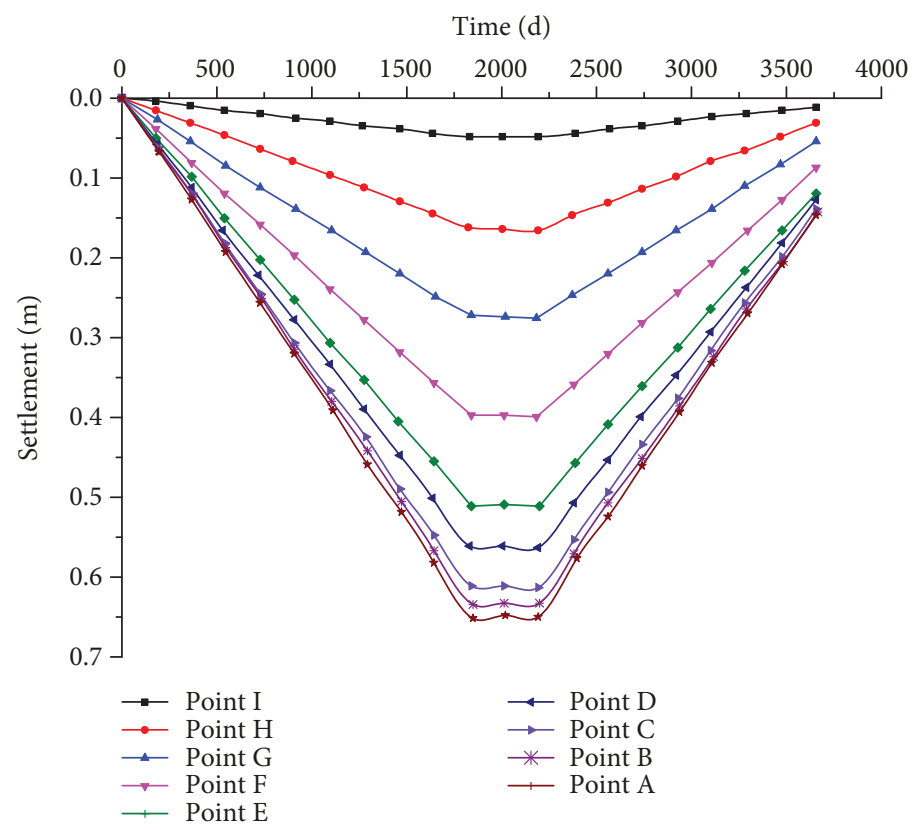

Figure 13: Ground settlement changing with time in case $\Pi-02$.

Figures 15(a) and 15(b) are the settlement proportions for different reasons at point $\mathrm{A}$ (depth $3.75 \mathrm{~m}$ ) and point $\mathrm{E}$ (depth $40.25 \mathrm{~m}$ ), respectively. Settlement caused by groundwater withdrawal and upper loading accounts for $98 \%$ of the total settlement from year 0 to 100 . Settlement caused by self-weight is larger than that caused by pumping and loading after 150 years. The settlement caused by soil selfweight accounts for $70 \%$ of the total settlement. Analysis shows that settlement caused by groundwater drainage and upper loading dominates within 200 years and settlement caused by self-weight gradually prevails and becomes larger than that of groundwater withdrawal and loading with the increasing depth of aquifers.

(2) The groundwater level gradually decreases from $0 \mathrm{~m}$ to $5 \mathrm{~m}$ with a velocity of $0.5 \mathrm{~m}$ per year; the loading intensity is $1 \mathrm{kPa}$

The comparison of settlement caused by self-weight, loading, and groundwater withdrawal is shown in Figure 16. As the groundwater table decreases, the settlement caused by groundwater withdrawal and soil self-weight 


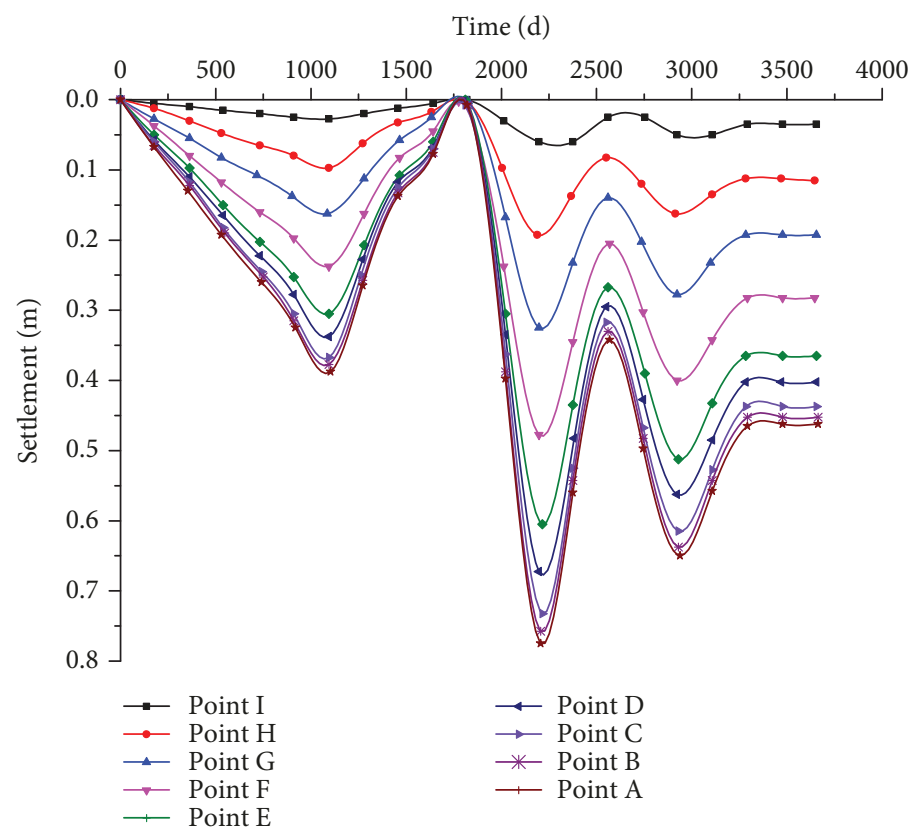

FIGURE 14: Ground settlement changing with time in case $\Pi-03$.

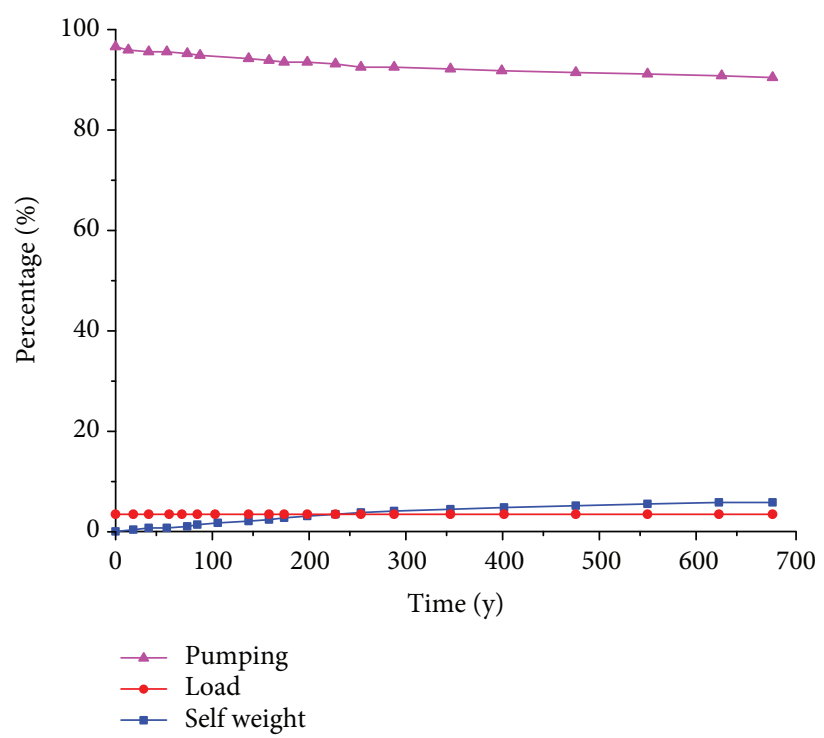

(a) Point A (depth $3.75 \mathrm{~m})$

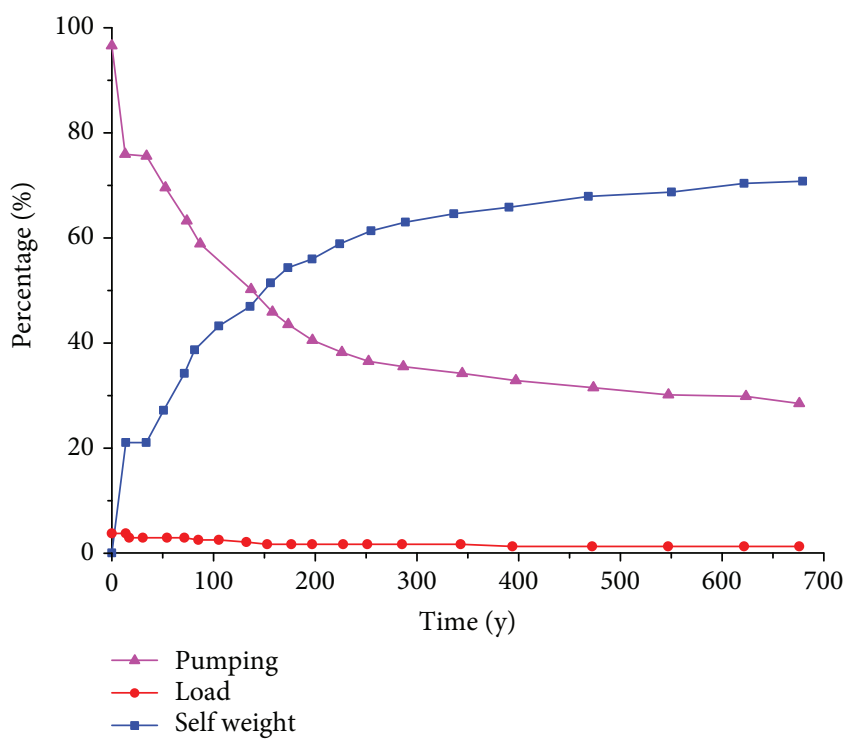

(b) Point E (depth $40.25 \mathrm{~m})$

Figure 15: Percentage of partial settlement and total settlement at groundwater level $4 \mathrm{~m}$.

increases, while load-induced settlement decreases, resulting in an increasing percentage of ground settlement caused by pumping and self-weight (Figure 16(a)). Settlement caused by pumping and loading almost accounts for $95 \%$ of the total settlement at the first hundred years. Soil self-weight increases with the increase of depth. Settlement caused by soil self-weight reaches to $60 \%$ of the total settlement in a short time which exceeds the settlement caused by groundwater withdrawal and upper loading.

Settlement caused by groundwater withdrawal and selfweight increases with groundwater depth which results in the percentage of settlement caused by loading decreasing at the same time. Settlement caused by groundwater withdrawal has the highest percentage, settlement caused by loading is smaller, and settlement caused by self-weight is the smallest when the aquifer is buried shallow. Settlement caused by self-weight has the highest percentage and settlement caused by drainage is smaller while loading accounts for the smallest when the aquifer is deeply buried.

(3) The initial upper loading is assumed to be $1 \mathrm{kPa}$ and increases to the assumed maximum upper loading of $500 \mathrm{kPa}$ (Table 7) 


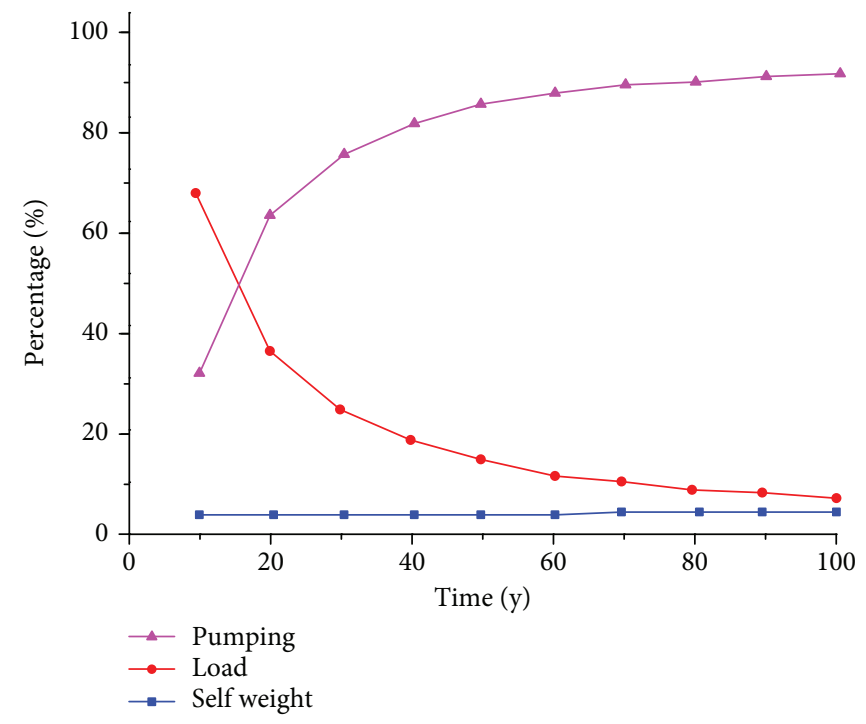

(a) Point A (depth $3.75 \mathrm{~m})$

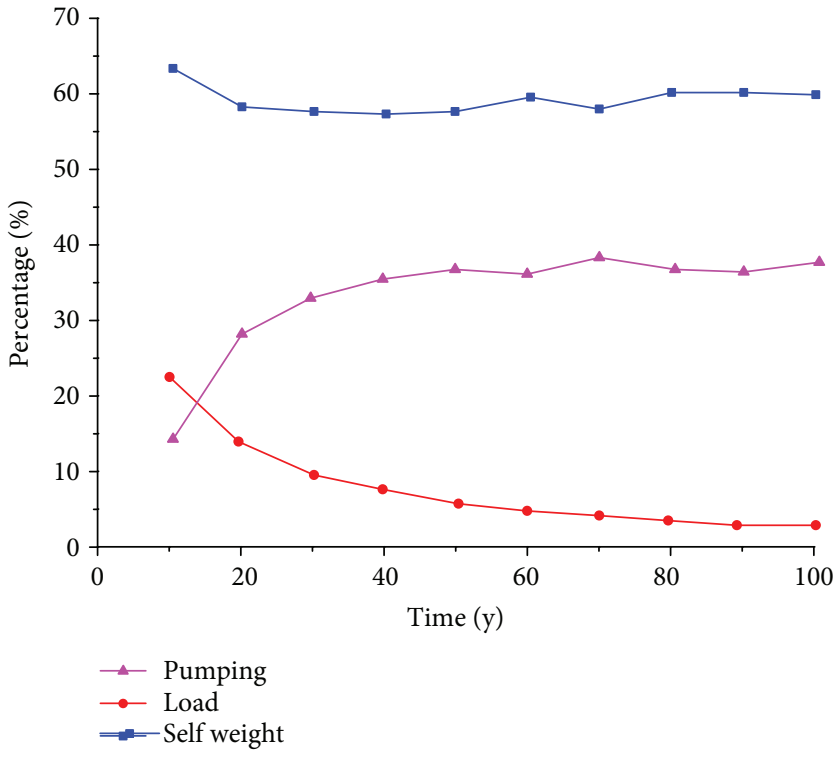

(b) Point E (depth $40.25 \mathrm{~m}$ )

FIGURE 16: Percentage of partial settlement and total settlement with changing phreatic water level.

TABLE 7: Variation of groundwater depth and load intensity.

\begin{tabular}{|c|c|c|c|c|c|c|c|c|c|c|c|}
\hline \multirow{2}{*}{ Plan } & \multirow{2}{*}{ Load $(\mathrm{kPa})$} & \multicolumn{10}{|c|}{ Groundwater depth (m) } \\
\hline & & $10^{\text {th }}$ & $20^{\text {th }}$ & $30^{\text {th }}$ & $40^{\text {th }}$ & $50^{\text {th }}$ & $60^{\text {th }}$ & $70^{\text {th }}$ & $80^{\text {th }}$ & $90^{\text {th }}$ & $100^{\text {th }}$ \\
\hline IV-01 & 1 & -0.5 & -1.0 & -5.0 & -8.0 & -10.0 & -15.0 & -20.0 & -25.0 & -30.0 & -40.0 \\
\hline IV -02 & 5 & -0.5 & -1.0 & -5.0 & -8.0 & -10.0 & -15.0 & -20.0 & -25.0 & -30.0 & -40.0 \\
\hline IV -03 & 10 & -0.5 & -1.0 & -5.0 & -8.0 & -10.0 & -15.0 & -20.0 & -25.0 & -30.0 & -40.0 \\
\hline IV-04 & 100 & -0.5 & -1.0 & -5.0 & -8.0 & -10.0 & -15.0 & -20.0 & -25.0 & -30.0 & -40.0 \\
\hline IV-05 & 500 & -0.5 & -1.0 & -5.0 & -8.0 & -10.0 & -15.0 & -20.0 & -25.0 & -30.0 & -40.0 \\
\hline
\end{tabular}

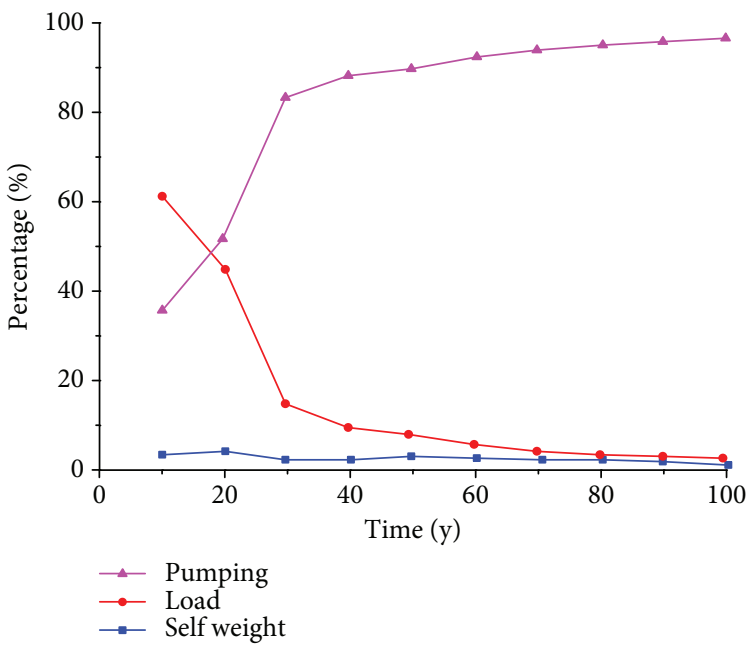

(a) Point A (depth $3.75 \mathrm{~m})$

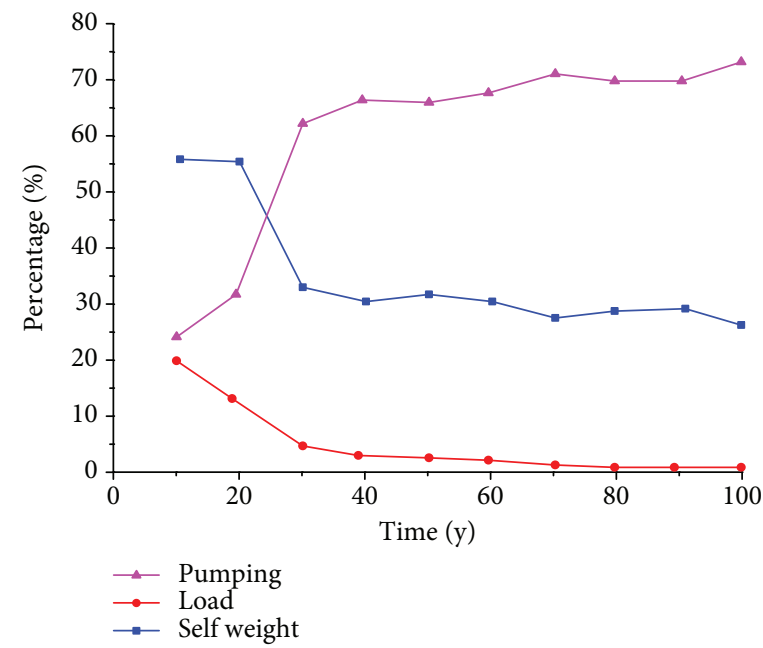

(b) Point E (depth $40.25 \mathrm{~m}$ )

Figure 17: Percentage of settlement caused by different reasons when loading intensity is $1 \mathrm{kPa}$.

The upper loading increases gradually to investigate the settlement caused by loading intensity. The groundwater level in the II confined aquifer decreases from $0 \mathrm{~m}$ to $40 \mathrm{~m}$ below the ground surface in 100 years. Settlement caused by each factor and total settlement are shown in Figures 17-19.

Figure 17 shows that settlement caused by groundwater withdrawal can be much more significant than the other 


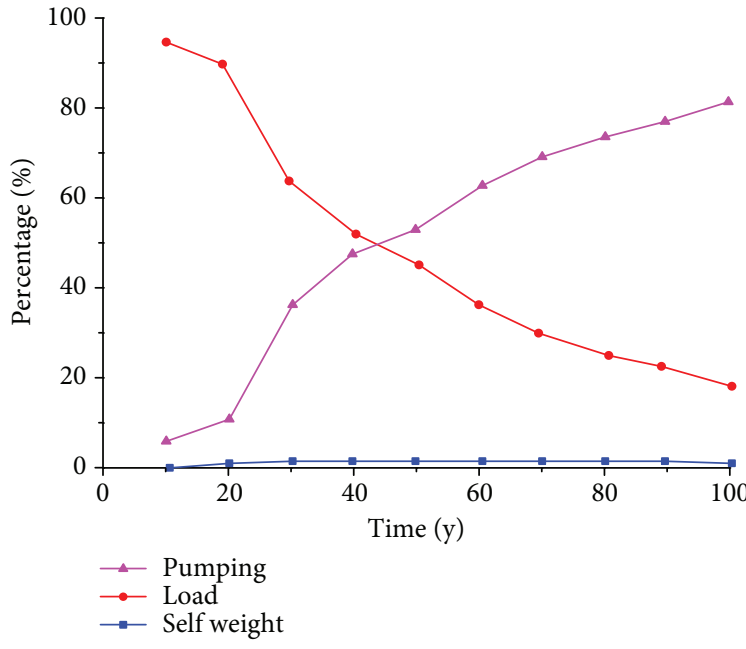

(a) Point A (depth $3.75 \mathrm{~m}$ )

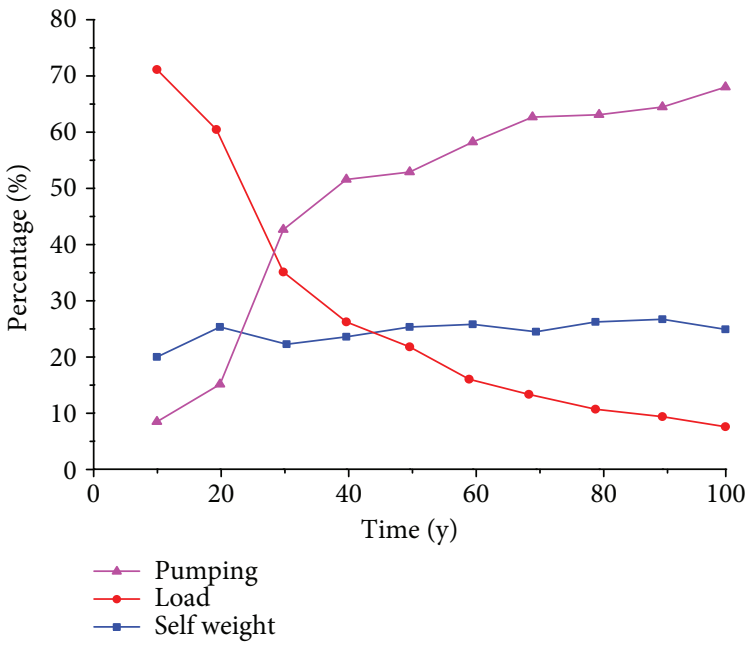

(b) Point E (depth $40.25 \mathrm{~m}$ )

FIGURE 18: Percentage of settlement caused by different reasons when loading intensity is $10 \mathrm{kPa}$.

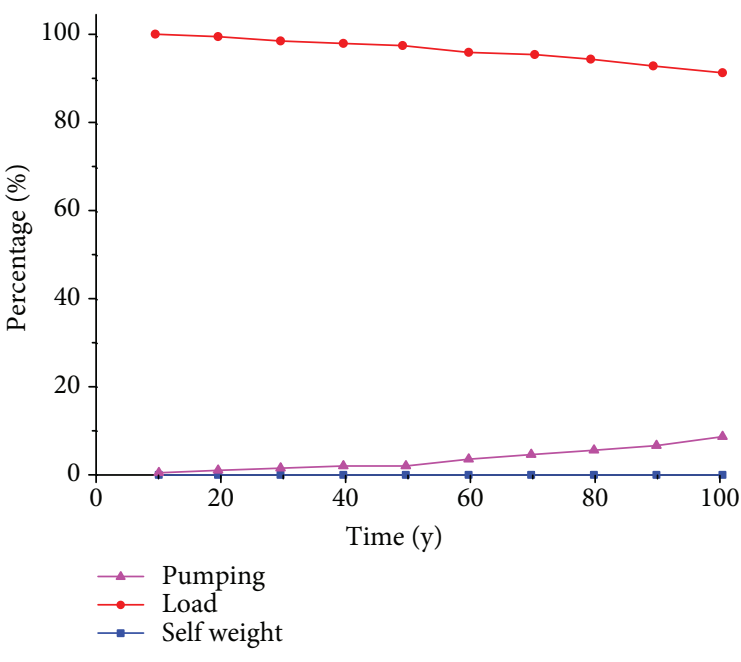

(a) Point A (depth $3.75 \mathrm{~m}$ )

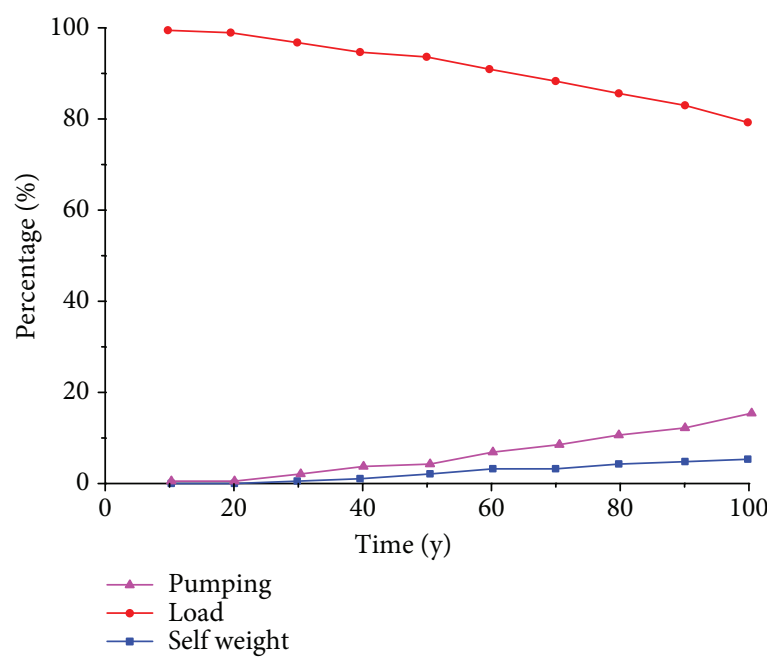

(b) Point E (depth $40.25 \mathrm{~m}$ )

Figure 19: Percentage of settlement caused by different reasons when loading intensity is $500 \mathrm{kPa}$.

factors, i.e., the self-weight and loading intensity. The percentage of loading-induced settlement decreases with the soil depth, as compared to those between point A and point E. Settlement caused by soil self-weight accounts for almost $30 \%$ of the total settlement when the soil is deeply buried. Figure 18 shows that settlement caused by loading and soil self-weight increases with the loading intensity and buried depth. Settlement caused by loading accounts for the largest percentage of total settlement when the loading magnitude is $500 \mathrm{kPa}$ while settlement caused by groundwater withdrawal and self-weight is relatively small (Figure 19).

To sum up, land subsidence caused by loading increases with the loading intensity and decreases with the buried depth and the contribution of groundwater withdrawal and selfweight decreases with the loading intensity. Settlement caused by groundwater withdrawal accounts for most of the total settlement and increases with time at the depth of $40.25 \mathrm{~m}$. And settlement caused by loading and soil self-weight decreases with the loading intensity at the same depth. The percentage of settlement caused by soil self-weight decreases with the loading intensity which is smaller than settlement caused by groundwater withdrawal. Settlement caused by soil selfweight accounts for the smallest percentage of total settlement at the depth of $3.75 \mathrm{~m}$ at any load intensities.

\section{Conclusions}

The column element settlement model is established to consider the soil anisotropic properties in horizontal direction. The numerical model was calibrated against the monitored data in the study area and then further applied to investigate the percentage of land subsidence induced by soil self-weight, upper loading, and groundwater withdrawal. The main conclusions are summarized below: 
(1) The column element settlement model is proposed, and soil parameters from field tests were adopted to the numerical model. The new model can be used to investigate the coupling effect of soil self-weight, upper loads, and groundwater withdrawal on land subsidence

(2) The predicted land subsidence shows good agreement with the monitored results. Land subsidence caused by soil self-weight increases with time and groundwater depth. Land subsidence increases gradually with the load intensity and time

(3) Normalized land subsidence was adopted to evaluate the percentage of land subsidence caused by different reasons. Land subsidence caused by groundwater withdrawal prevails through the whole monitoring period except for upper load intensities over $500 \mathrm{kPa}$. Settlement induced by soil self-weight and upper loads varies with different loadings and depths. The proportion of land subsidence caused by soil selfweight, upper loads, and groundwater withdrawal varies with examining time

The simulation procedure proposed in this study is quite generic and can be easily extended to simulate more sophisticated soil layer distributions. While a more appropriate soil constitutive model should be developed to satisfy different soil properties due to the complex deformation characteristics, which could be elastic, elastoplastic, and viscoelastic. The percentage of land subsidence induced by groundwater withdrawal is the main culprit for large ground deformation which deserves more attention in practical engineering.

\section{Data Availability}

The data used to support the findings of this study are included within the article.

\section{Conflicts of Interest}

The authors declare that there is no conflict of interest regarding the publication of this paper.

\section{Acknowledgments}

This study was supported by the National Natural Science Foundation of China (Grant no. 51878127).

\section{References}

[1] Z. Cui and Y. Tang, "Domestic and international recent situation and research of land subsidence disasters," Northwestern Seismological Journal, vol. 29, no. 3, pp. 275-278, 2007.

[2] J. Hu, Z. Sui, and J. Chen, "Study on geological environmental effect after banning groundwater drainage in Su-Xi-Chang area," Jiangsu Geology, vol. 30, no. 4, pp. 261-264, 2006.

[3] K. S. Li, "Predicting the density profile and settlement of marine deposits," in Proc. of International Conference on Computational Methods in Structural and Geotechnical
Engineering Hong Kong, pp. 1562-1567, China Translation \& Printing Services Ltd, 1994.

[4] A. K. Gabriel, R. M. Goldstein, and H. A. Zebker, "Mapping small elevation changes over large areas: differential radar interferometry," Journal of Geophysical Research, vol. 94, no. B7, pp. 9183-9191, 1989.

[5] H. Jiang, "Problems and discussion in the study of land subsidence in the Suzhou-Wuxi-Changzhou area," Quaternary Sciences, vol. 25, no. 1, pp. 29-33, 2005.

[6] J. Qian and Z. Yin, Principle and Calculation of Geotechnical Engineering, China Water Conservancy and Hydropower Press, Beijing, 1996.

[7] P. Teatini, M. Ferronato, G. Gambolati, and M. Gonella, "Groundwater pumping and land subsidence in the EmiliaRomagna coastland, Italy: modeling the past occurrence and the future trend," Water Resources Research, vol. 42, no. 1, 2006.

[8] J. Sundell, E. Haaf, T. Norberg, C. Alén, M. Karlsson, and L. Rosén, "Risk mapping of groundwater-drawdown-induced land subsidence in heterogeneous soils on large areas," Risk Analysis, vol. 39, no. 1, pp. 105-124, 2019.

[9] D. L. Galloway, The Frequency Dependence of Aquifer System Elastic Storage Coefficients-Implications for Estimates of Aquifer Hydraulic Properties and Aquifer System Compaction, U. S. Geological Survey, Sacramento, 1995.

[10] G. G. Meyerhof, "Shallow foundations," Journal of Soil Mechanics \& Foundations Division ASCE, vol. 19, no. SM2, pp. 21-31, 1965.

[11] J. E. T. Moncur and R. L. Pollock, "Scarcity rents for water: a valuation and pricing model," Land Economics, vol. 64, no. 1, pp. 62-72, 1988.

[12] X. Wang, Finite Layer Analysis of Ground Settlement Caused by Drainage, Hohai University, Nanjing, 2007.

[13] T. J. Burbey, "Stress-strain analyses for aquifer-system characterization," Ground Water, vol. 39, no. 1, pp. 128-136, 2001.

[14] A. A. Fungaroli and S. R. Pranger, "Unit weights of a normally consolidated soil," in Proc. of 7th international conference on soils Mechanics and Foundation Engineering, pp. 131-134, Mexico, 1969.

[15] R. Bravo, J. R. Rogers, and T. G. Cleveland, Analysis of Groundwater Level Fluctuations and Borehole Extensometer Data from the Baytown Area, Houston, TX. Land Subsidence, International Association of Hydrological Sciences Publication 12-18, Washington, 1991.

[16] J. B. Burland, M. Burbidge, E. Wilson, and TERZAGHI, "Settlement of foundations on sand and gravel," Proceedings of the Institution of Civil Engineers, vol. 78, no. 6, pp. 13251381, 1985.

[17] R. W. Hexem and E. Heady, Water Production Function for Irrigated Agriculture, Iowa State University Press, 1978.

[18] R. L. Johnson and G. V. Johnson, Economic Valuation of Natural Resources: Issues, Theory and Applications, Westiview Press, Boulder. Colorado, 1990.

[19] G. Li, Advanced Soil Mechanics, Tsinghua University Press, Beijing, 2006.

[20] B. Li, Study of Large Strain Consolidation Theory in Layered Soft Clay Soil Foundation, Zhejiang University, Hangzhou, 1999.

[21] M. W. A. Van der Kooij, D. V. Halsema, W. Groenewoud et al., "Satellite Radar Measurements for Land Subsidence Detection," in Proceedings of Land Subsidence, Barends and Schroder, Balkema, Rotterdam, 1995. 
[22] S. Ye and S. Dai, "Comparing of results of two dimensional, quasi three dimensional and three dimensional models for groundwater," Hydrogeology \& Engineering Geology, vol. 30, no. 5, pp. 23-27, 2003.

[23] X. Shi, R. Fang, J. Wu, H. Xu, Y. Sun, and J. Yu, "Sustainable development and utilization of groundwater resources considering land subsidence in Suzhou, China," Engineering Geology, vol. 124, pp. 77-89, 2012.

[24] V. K. Barwell and D. R. Lee, "Determination of horizontal-tovertical hydraulic conductivity ratios from seepage measurements on lake beds," Water Resources Research, vol. 17, no. 3, pp. 565-570, 1981.

[25] S. Ye, Y. Wang, J. Wu et al., "Characterization of earth fissures in South Jiangsu, China," Proceedings of the International Association of Hydrological Sciences, vol. 372, pp. 249-253, 2015.

[26] G. Y. Wang, G. You, B. Shi, Z. L. Qiu, H. Y. Li, and M. Tuck, "Earth fissures in Jiangsu Province, China and geological investigation of Hetang earth fissure," Environmental Earth Sciences, vol. 60, no. 1, pp. 35-43, 2010.

[27] Y. S. Xu, S. L. Shen, Z. Y. Cai, and G. Y. Zhou, "The state of land subsidence and prediction approaches due to groundwater withdrawal in China," Natural Hazards, vol. 45, no. 1, pp. 123-135, 2008.

[28] Y. Chen, W. Zhao, J. Y. Han, and P. J. Jia, "A CEL study of bearing capacity and failure mechanism of strip footing resting on $c-\varphi$ soils," Computers and Geotechnics, vol. 111, pp. 126136, 2019.

[29] S. Qi, F. Wu, Z. Ding, and T. Liu, "Study on mechanism of deep fractures of Jinping first stage hydropower station by engineering geology analogy," Chinese Journal of Rock Mechanics and Engineering, vol. 8, p. 033, 2004.

[30] Z. Wang, Y. Zhang, J. Wu, J. Yu, and X. Gong, "Numerical simulation of earth fissures due to groundwater withdrawal," Proceedings of the International Association of Hydrological Sciences, vol. 372, pp. 395-398, 2015.

[31] C. Peng and G. Yang, "A simplified method for determining ep curve of soft soil and Its application to analyzing nonlinear settlement of foundation," Rock and Soil Mechanics, vol. 29, no. 6, pp. 1706-1710, 2008.

[32] J. Lovisa, W. Read, and N. Sivakugan, "Time factor in consolidation: critical review," International Journal of Geomechanics, vol. 13, no. 1, pp. 83-86, 2013. 

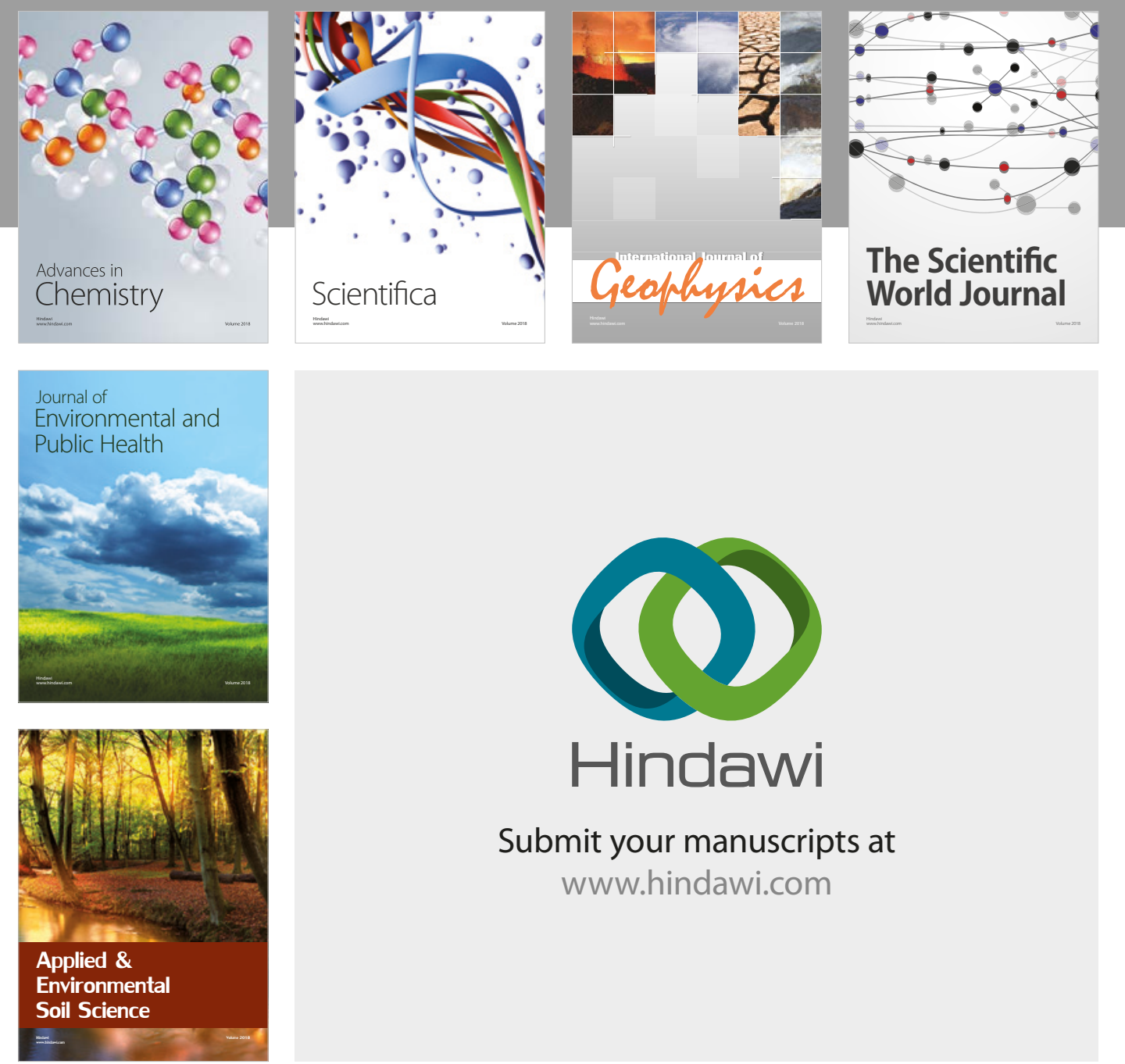

The Scientific

\section{World Journal}
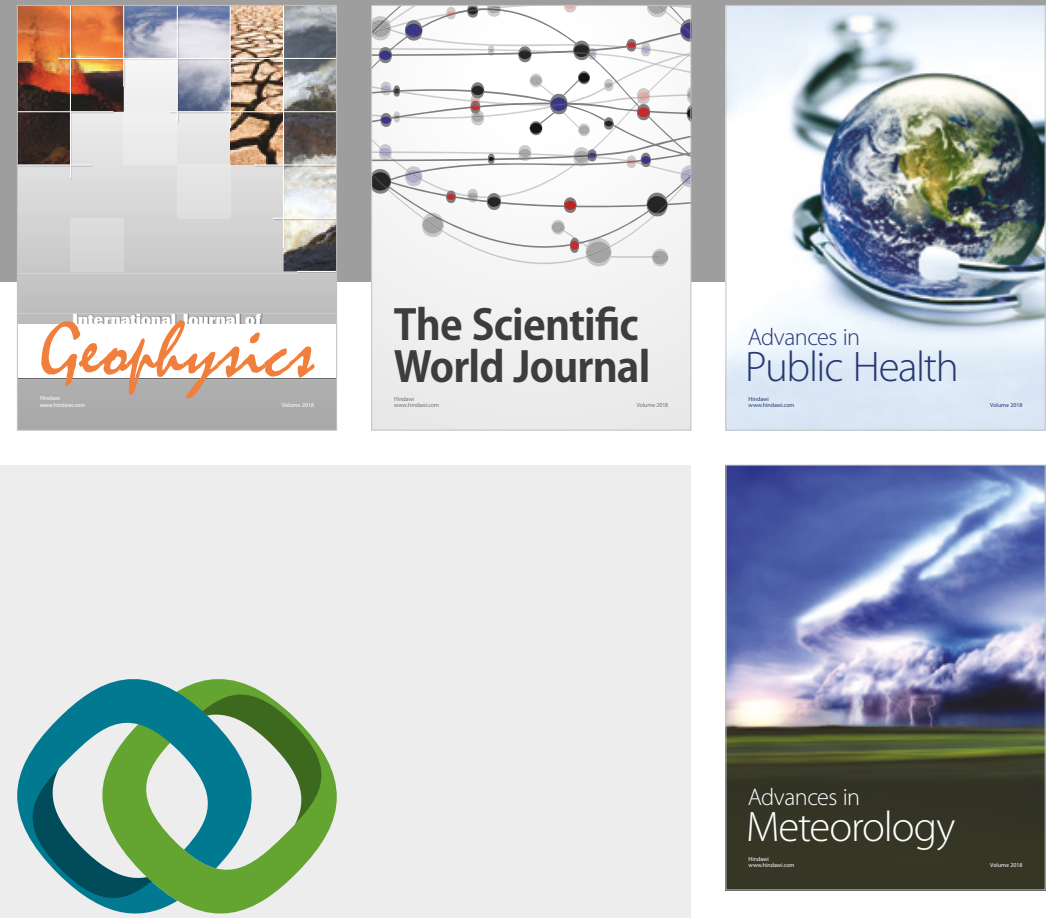

Advan

Public Health

\section{Hindawi}

Submit your manuscripts at

www.hindawi.com
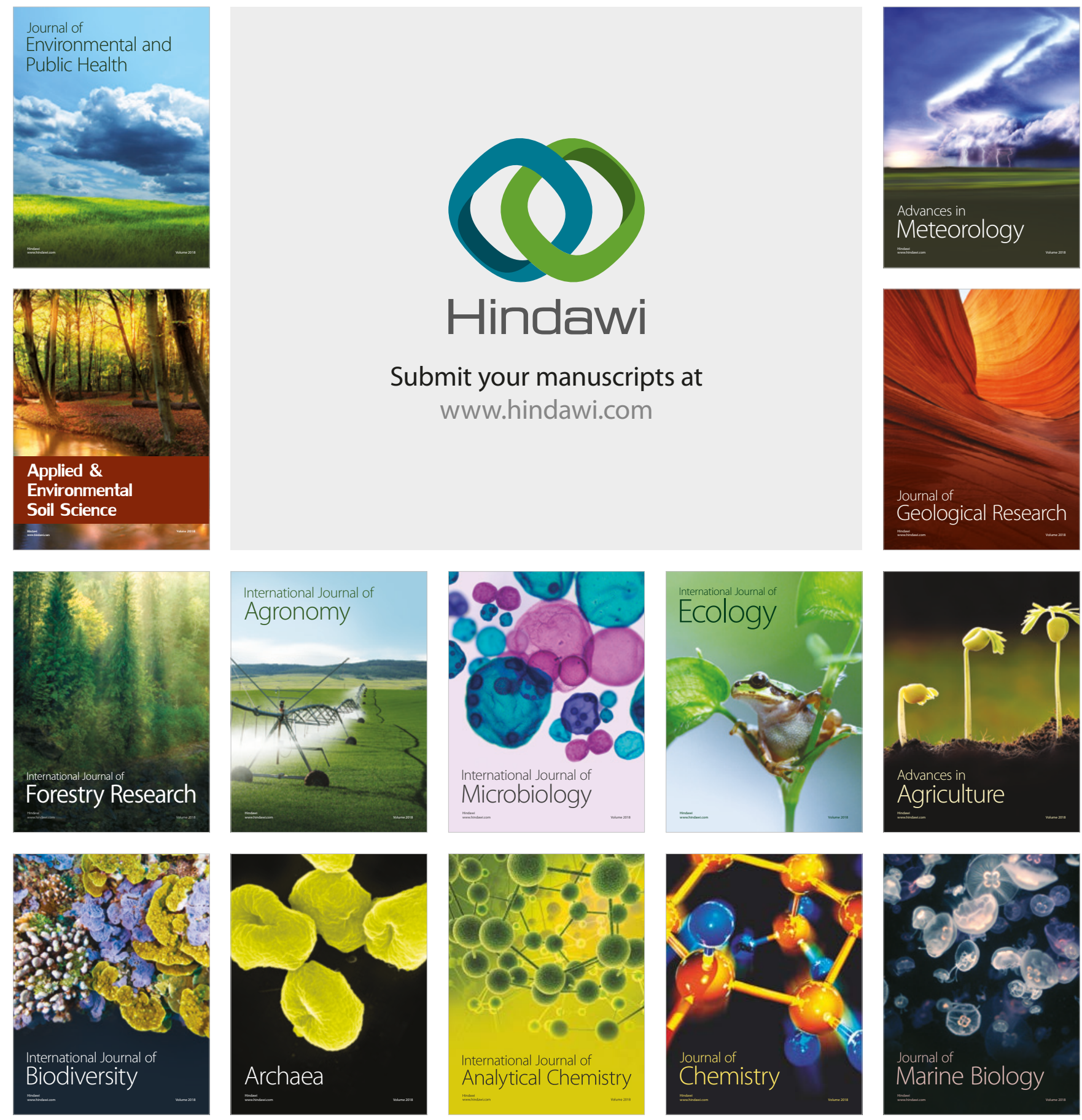